\title{
Current Landscape: The Mechanism and Therapeutic Impact of Obesity for Breast Cancer
}

\author{
Chongru Zhao ${ }^{\dagger}$, Weijie $\mathrm{Hu}^{+}$, Yi Xu ${ }^{\dagger}$, Dawei Wang, Yichen Wang, Wenchang Lv, \\ Mingchen Xiong, Yi Yi, Haiping Wang ${ }^{*}$ Qi Zhang ${ }^{*}$ and Yiping Wu*
}

Department of Plastic Surgery, Tongji Hospital, Tongji Medical College, Huazhong University of Science and Technology, Wuhan, China

OPEN ACCESS

Edited by: San-Gang Wu,

First Affiliated Hospital of Xiamen University, China

Reviewed by:

Frank Stanczyk,

University of Southern California,

United States

Ines Barone,

University of Calabria, Italy

${ }^{*}$ Correspondence:

Haiping Wang

Wanghpwanghp@163.com

Qi Zhang

806430787@qq.com

Yiping Wu

tongjiplastic@163.com

${ }^{\dagger}$ These authors have contributed equally to this work and

share first authorship

Specialty section: This article was submitted to Breast Cancer,

a section of the journa

Frontiers in Oncology

Received: 04 May 2021

Accepted: 05 July 2021

Published: 19 July 2021

Citation:

Zhao C, Hu W, Xu Y, Wang D, Wang Y, $L v W$, Xiong $M$, Yi Y, Wang $H$, Zhang $Q$ and Wu Y (2021) Current Landscape:

The Mechanism and Therapeutic Impact of Obesity for Breast Cancer.

Front. Oncol. 11:704893.

doi: 10.3389/fonc.2021.704893
Obesity is defined as a chronic disease induced by an imbalance of energy homeostasis. Obesity is a widespread health problem with increasing prevalence worldwide. Breast cancer (BC) has already been the most common cancer and one of the leading causes of cancer death in women worldwide. Nowadays, the impact of the rising prevalence of obesity has been recognized as a nonnegligible issue for BC development, outcome, and management. Adipokines, insulin and insulin-like growth factor, sex hormone and the chronic inflammation state play critical roles in the vicious crosstalk between obesity and BC. Furthermore, obesity can affect the efficacy and side effects of multiple therapies such as surgery, radiotherapy, chemotherapy, endocrine therapy, immunotherapy and weight management of BC. In this review, we focus on the current landscape of the mechanisms of obesity in fueling $\mathrm{BC}$ and the impact of obesity on diverse therapeutic interventions. An in-depth exploration of the underlying mechanisms linking obesity and BC will improve the efficiency of the existing treatments and even provide novel treatment strategies for $\mathrm{BC}$ treatment.

Keywords: breast cancer, obesity, adipokines, risk, outcomes, therapy

\section{INTRODUCTION}

Breast cancer $(\mathrm{BC})$ is ranked as the most common malignancy and the major leading cause of cancer-related death among women worldwide (1). The main reason is that advanced BC is frequently confronted with a high rate of relapse, invasion, and metastasis, especially the organotropic metastasis capacity to the brain and lung (2). Obesity is a pivotal lifestyle driver of the current and prospective $\mathrm{BC}$ rates. According to the individually calculated body mass index (BMI), the World Health Organization (WHO) has defined that obesity class I-III has a BMI $\geq 30$ $\mathrm{kg} / \mathrm{m}^{2}$ at baseline and BMI $<30 \mathrm{~kg} / \mathrm{m}^{2}$ is considered non-obese (3). Numerous epidemiological studies have authenticated that obesity is an important risk factor for $\mathrm{BC}$, which means that obesity is not only associated with the incidence of $\mathrm{BC}$, but also related to poor prognosis, high incidence, and decreased survival rate in BC patients (4).

Obesity is defined as a chronic disease induced by an imbalance of energy homeostasis. In obesity, metabolic disorders occur in adipose tissues, leading to the secretion of many proinflammatory cytokines, growth factors, and hormones, which in turn contribute to the 
formation of the tumor microenvironment (TME) and the progression of cancer within the breast tissue. Although biological explanations of how obesity affects $\mathrm{BC}$ have been widely discussed, the role of obesity during $\mathrm{BC}$ initiation and development remains incompletely mapped and being constantly updated. Like other types of cancer, until today, the main treatment of BC is still surgical resection and radiotherapy, which is an indispensable part of the treatment of local lesions. The metastasis and occurrence of $\mathrm{BC}$ continue to lead to unacceptable cancer-related deaths, leading to the diverse methods of chemotherapy, hormone therapy, and immunotherapy. Existing researches have shown that obesity can affect the effectiveness of conventional BC treatments and further lead to therapeutic resistance. This article will summarize the latest studies on the functions and mechanisms of obesity in $\mathrm{BC}$, including the disorders of adipokines, insulin, and insulinlike growth factor (IGF), endogenous sex hormones, chronic inflammation. It also summarized the impact of obesity on BC therapy, such as surgery, radiotherapy (RT), chemotherapy, endocrine therapy (ET) and immunotherapy, and weight management in BC. An in-depth understanding of the mechanisms linking obesity and $\mathrm{BC}$, as well as the impact of obesity on the effectiveness and tolerance of $\mathrm{BC}$ treatment, is paramount for establishing new strategies for the prevention and therapeutic interventions of BC.

\section{OBESITY AND THE RISK FACTORS OF BREAST CANCER}

The excess weight gain of women during adulthood can increase the risk of $\mathrm{BC}$, and can even lead to an earlier onset of $\mathrm{BC}$ and a worse prognosis (5). Patients hospitalized for overweight and obesity are associated with an increased risk of several specific cancers, including $\mathrm{BC}$, compared to the general population (6). Among obese women, BC risk factors have been found to differ in menopausal status, tumor subtypes, and some other conditions.

The relationship between obesity and $\mathrm{BC}$ is intricate. The associations appeared to be extremely consistent for

\footnotetext{
Abbreviations: BC, Breast Cancer; BMI, Body Mass Index; WHO, World Health Organization; TME, Tumor Microenvironment; IGF, Insulin-like Growth Factor; RT, Radiotherapy; ET, Endocrine Therapy; TNBC, Triple-negative BC; OS, Overall Survival; BMBC, Brain Metastases from BC; EMT, Epithelial-toMesenchymal Transition; PDX, Patient-derived Xenograft; obASCs, Obesityaltered Adipose Stem Cells; DIO, Diet-induced Obesity; CSC, Cancer Stem Cell; MDSCs, Myeloid-derived Suppressor Cells; FAO, Fatty Acid $\beta$-oxidation; HFD, High-fat Diet; SFRP5, Secreted Frizzled-related Protein 5; InsR, Insulin Receptor; RFS, Recurrence-free Survival; IGF-1, Insulin-like Growth Factor 1; ASCs, Adipocyte-derived Stem Cells; CCL2, CC Chemokine Ligand 2; COX-2, Cyclooxygenase-2; WAT, White Adipose Tissue; IL, Interleukin; TNF, Tumor Necrosis Factor; HIF-1 $\alpha$, Hypoxia-inducible Factor $1 \alpha$; CLSs, Crown-like Structures; PGE2, Prostaglandin E2; miRs, micro-RNAs; CRP, C-reactive Protein; pCR, Pathological Complete Response; Dox, Doxorubicin; CRF, Cancer-related Fatigue; AKR, Aldo-keto Reductase; CBR, Carbonyl Reductases; NAC, Neoadjuvant Chemotherapy; ASCO, American Society of Clinical Oncology; AIs, Aromatase Inhibitors; Tx, Tamoxifen; CTGF, Connective Tissue Growth Factor; T-DM1, Trastuzumab Emtansine.
}

postmenopausal $\mathrm{BC}$ that high obesity is a risk factor for $\mathrm{BC}$ in postmenopausal women independent of ethnic factors. Park et al. demonstrated that in postmenopausal women in Korea, there was a positive relationship between obesity and $\mathrm{BC}$ (7). This may attribute to the higher estrogen levels produced in adipose tissue in postmenopausal women (8). However, there is still controversy on their impact on the risk of premenopausal BC. The obesity impact on premenopausal BC risk might be a positive correlation, negative correlation, or even irrelevant, which is involved in ethnic differences or/and sample size of the clinical trial. The fact that many previous studies performed in the Western population with a negative association and Asian studies showed uncertain associations between obesity and $\mathrm{BC}$, indicates the ethnic and racial importance in premenopausal $\mathrm{BC}$ risk. For example, a systematic analysis of premenopausal $\mathrm{BC}$ suggested a negative association of obesity and BC risk in premenopausal Caucasian and African women (9). Similarly, the investigation among over 6 million Korean women in 2020 suggested that there was a negative association between obesity and BC in premenopausal women (7). However, multiple studies in Asian premenopausal women indicated no significant effect of obesity on the risk of BC during the premenopausal period (10) (11). In addition, Jeong et al. demonstrated an increased risk of triple-negative BC (TNBC) in obese type II $\left(\mathrm{BMI} \geq 30 \mathrm{~kg} / \mathrm{m}^{2}\right)$ premenopausal Korean women (12). This study was consistent with the finding of a meta-analysis, which revealed the significant positive association of obesity and overweight with $\mathrm{BC}$ during the premenopausal period in Asian women (13).

Epidemiological data suggested that large disparities are presented in the prevalence of obesity and overweight among women in different populations. In general, different ethnic groups vary in body size, body composition, and fat composition, and body fat distribution, which might result in subtle differences in metabolic levels and BC risk. Compared with other ethnic groups, Asians seem to have higher overall fat levels and abdominal fat as well as lower lean body mass for a given BMI (14). Amadou et al. showed that an increase of $5 \mathrm{~kg} / \mathrm{m}^{2}$ in BMI was associated with a significant $5 \%$ reduction in premenopausal BC risk (9). Especially, there was an inverse relationship between obesity and the risk of premenopausal BC only among Africans and Caucasians, but there was a significant positive association was observed among Asian women (9). Briefly, the determinants of obesity are complex and diverse, which is concerned with biological alterations, socio-economic and other environmental and behavioral influences. And, ethnic and racial differences are a nonnegligible key factor in obesity and BC risk.

The effect of obesity on $\mathrm{BC}$ also varies with different $\mathrm{BC}$ subtypes. In obesity type II $\left(\mathrm{BMI} \geq 30 \mathrm{~kg} / \mathrm{m}^{2}\right)$, premenopausal women had an increased risk of TNBC, and postmenopausal women had an increased risk of Luminal A, Luminal B, HER2$B C$, and TNBC (12). Furthermore, a retrospective investigation of clinicopathological BC features of postmenopausal Japanese women indicated that compared with obese patients, mean values of the Ki67 labeling index were significantly higher in lean patients, and HER2+ tumors were more often found in lean patients (15). More aggressive tumors were observed in lean 
postmenopausal women, which contradicted the prevailing perception of $\mathrm{BC}$ in obese women. In order to ascertain the relationship between obesity and BC risk in more refined tumor subtypes, Nattenmüller et al. evaluated six well-established immunohistochemical markers in BC samples (16). It suggested that obesity was related to the risk of breast tumors with lower aggressiveness such as ER+, PR+, HER2-, Ki67low, $\mathrm{Bcl}-2+$, and p53- tumors in postmenopausal women. Further mechanistic studies are required to underlie the associations, as well as larger-scale analyses of the pooled prospective cohort to investigate relationships between obesity and BC subtypes in more detail.

In addition to the traditional epidemiological studies, Shu et al. conducted Mendelian randomization analyses to assess the connection of BC risk with BMI and other indicators, using genetic instruments (17). They found genetically predicted obesity was associated with the BC risk regardless of age, menopausal status, ER status, and family history, unveiling the complex inter-relations of genetics, obesity, and BC risk. Nevertheless, Being overweight might not sufficient for the development of BC, which may be associated with LEP/LEPR gene polymorphisms. Liu et al. conducted a large case-control study among females in southwestern China and showed that persistent overweight (BMI $\geq 24 \mathrm{~kg} / \mathrm{m}^{2}$ ) along with LEPrs7799039 AA or LEPRrs1137100 GG genotypes synergistically increased the risk of BC (18). Bariatric surgery has been deemed as the most effective manner for obese patients to lose weight in both the short and long term, and is more effective in producing sustained weight loss than dieting. It was interesting that bariatric surgery was significantly relevant to reduced $\mathrm{BC}$ risk, both for cancer incidence and mortality, by a meta-analysis (19). Finally, further research into the complex association of obesity and BC risk will help to guide $\mathrm{BC}$ prevention.

\section{OBESITY AND OUTCOMES OF BREAST CANCER}

As Vernaci et al. proposed that, there was a negative impact of obesity on the prognosis in a population of BC patients (20). Over a long period of follow-up, a high BMI was associated with increased rates of relapse, second primary tumors, and death occurrence. The effect of BMI on the prognosis of BC depends on many factors, including tumor subtype, menopausal status, and age. In HR+ HER2- patients, obesity played a negative prognostic role in both pre-menopausal and post-menopausal women in the Asian population (21). Besides, in a crosssectional study, compared with women of normal weight, obese and morbidly obese women were affected by advanced HER2+ BC with histological grades 2 or 3 (22). Wang et al. found that in Hebei, China, BC patients with a high BMI were at greater risk of poor prognosis than $\mathrm{BC}$ patients with a low BMI, especially in patients over 50 years of age (23). One possible key to improving $\mathrm{BC}$ outcomes is to maintain an appropriate $\mathrm{BMI}$ for $\mathrm{BC}$ patients. However, the conclusion regarding the role of obesity as a prognostic indicator in $\mathrm{BC}$ individuals remains inconsistent worldwide. The study of Cacho-Díaz et al. reported that no association was found between overall survival (OS) and either patient with brain metastases from $\mathrm{BC}(\mathrm{BMBC})$ with a $\mathrm{BMI}>25 \mathrm{~kg} / \mathrm{m}^{2}$ or normal weight in Mexico (24). A study conducted in New Zealand showed that obesity was not associated with inferior locoregional control or survival outcomes, supporting the practice of continuing to offer breast-conserving treatment for women regardless of BMI (25). Thus, studies are still needed to continue maturing the definition of BMI in predicting $\mathrm{BC}$ prognosis under different situations. On all accounts, this will ultimately provide a reliable basis for the individualized prevention and treatment of BC.

\section{MECHANISMS LINKING OBESITY AND BREAST CANCER}

It is well-acknowledged that there is an intensive epidemiological link between obesity and $\mathrm{BC}$ incidence, but the underlying mechanism is very complicated in the obesity-driven BC progress. The increased or dysfunctional adipose tissue is directly associated with increased levels of many adiposederived factors, thus creating an environment that encourages BC cancerization. Nowadays, the proposed mechanisms in this process mainly include adipokines, insulin and IGF, sex hormone, and chronic inflammation, in which dysregulation can increase BC incidence, progression, and worsen clinical outcomes (Figure 1). It is interesting to note that obesity reinforces the activation of the inflammatory cascade for $\mathrm{BC}$ carcinogenesis. Concretely, the adipokines, such as leptin, adiponectin, resistin, and other adipokines like visfatin, secreted frizzled-related protein 5 (SFRP5), play an indispensable role in the manipulation of obesity-associated BC. Overall, these factors contribute to the obesity-induced pro-inflammatory milieu, as well as the crosstalk between adipocytes, immune cells, and breast epithelial cells, which are beneficial for BC risk. The thorough elucidation of the link between obesity and BC will undoubtedly provide the key clues for $\mathrm{BC}$ prevention and treatment.

\section{Adipokines}

Adipokines are soluble factors produced by adipocytes, including a large proportion of bioactive metabolites, lipids, and bioactive peptides, and over 600 adipokines have been identified so far. In the obesity state, the levels of adipokines are usually in an imbalanced state. The obesity-induced adipokines play a critical and complex role in driving the malignant phenotype of $\mathrm{BC}$ via endocrine, paracrine, and autocrine pathways. Among them, leptin and adiponectin are the most studied classic adipokines associated with obesity-triggered BC progression. It was reported that the increased level of leptin in obesity could promote $\mathrm{BC}$ initiation, progression, metastasis, and resistance to therapy through a variety of mechanisms including the activation of PI3K/Akt, JAK/AKT/STAT, and FAK-Src 


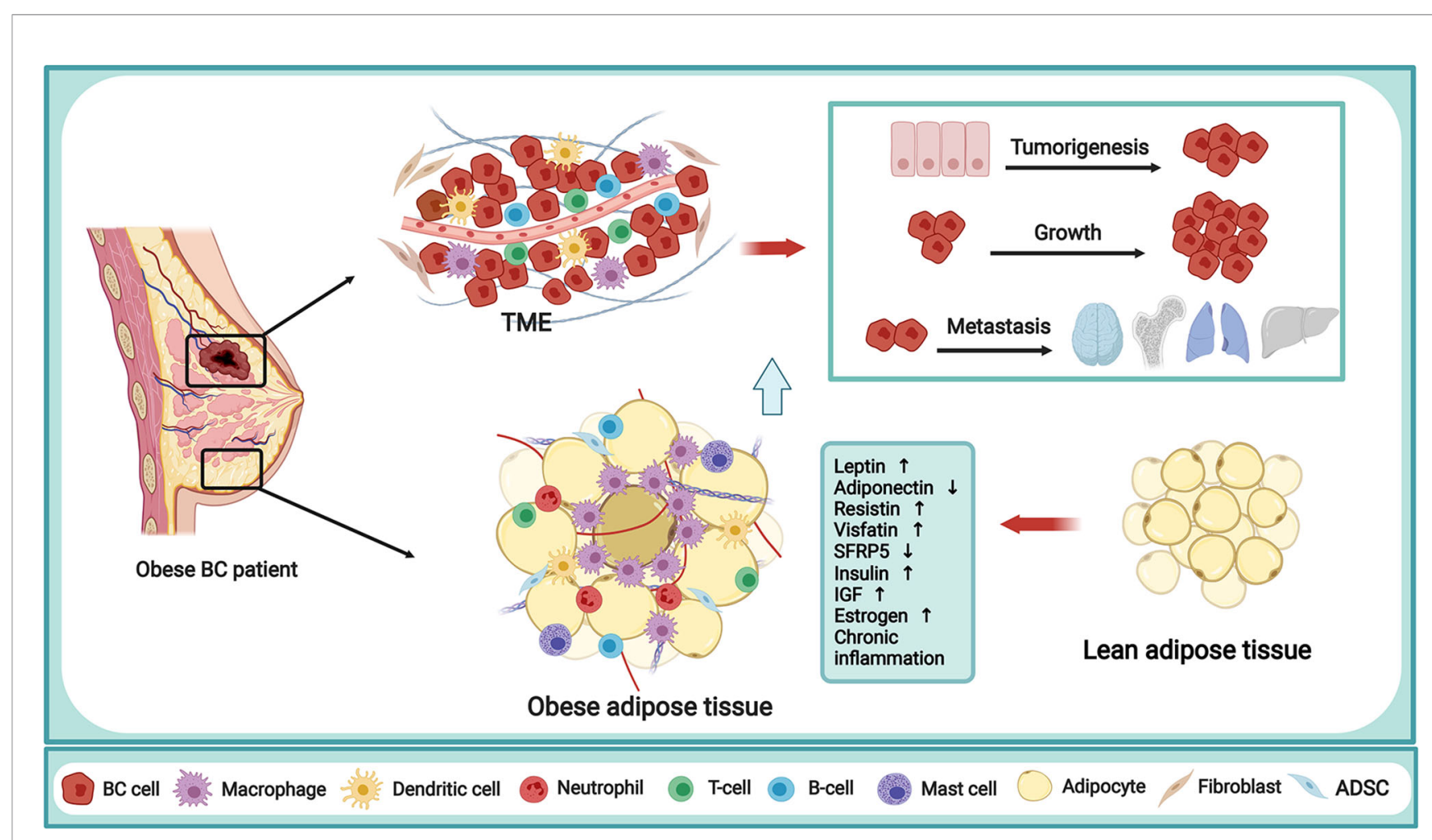

FIGURE 1 | Mechanism of obesity in fueling breast cancer. Obesity is a complex abnormal state, accompanied by various alterations capable of regulating the behavior of BC cells and TME. The obese adipose tissue in BC patient is directly related to the secretion of multiple adipokines, increased levels of insulin, IGF and endogenous sex hormone, and the chronic inflammation state, thus creating a TME that encourages tumorigenesis, growth and metastasis of BC. BC, breast cancer; TME, tumor microenvironment; IGF,insulin-like growth factor; SFRP5, secreted frizzled-related protein 5; ADSC, adipose-derived stem cells. The figure was created with BioRender.com.

signaling pathway. In contrast, obesity results in a decreased expression level of adiponectin, which in turn accelerates the BC risk and progression. Notably, other adipokine disorders caused by obesity, including resistin, visfatin, and SFRP5, are also proved to be key orchestrators in BC oncogenesis and progression. The specific implicated mechanisms of main adipokines in regulating obesity-related BC were listed in Table 1.

\section{Leptin}

Among the diverse adipokines, leptin has been acknowledged as a key candidate molecule linking obesity and $\mathrm{BC}$, due to its vicious function in obese-related BC growth and metastasis. Leptin, a $16 \mathrm{kDa}$ protein hormone overexpressed in obesity, is a crucial adipokine that can regulate appetite satiety. Aberrant leptin signaling is a hallmark of obesity and has been recognized to influence BC biology within TME, showing the potential of serving as a biomarker for BC risk in overweight/obese women (50).

The disruption of apical polarity in mammary glands is a sign of $\mathrm{BC}$ onset. The normal breast tissue samples characterized by an elevated leptin/adiponectin transcriptional ratio for obesity showed the altered distribution of polarity markers at the apex, while leptin level in breast tissue increased with overweight and obesity (26). The elevated leptin disrupted epithelial polarity and promoted premalignant alterations of the mammary gland in obese mice involving the activation of the PI3K/Akt pathway, providing a molecular basis for early alterations in epithelial architecture during obesity-mediated cancer initiation (26). Mahbouli et al. detected the antioxidant responses in three human mammary epithelial cells and confirmed that different regulatory effects of leptin on oxidative status depend on the tumor status of different mammary epithelial cells (27). Obesityrelated leptin secretion may aggravate the carcinogenic effect of obesity on BC through the regulation of the cellular oxidative state. Obesity alters the activity of adipocytes or stem cells to acquire tumorigenic properties, which are subsequently recruited into the TME with high levels of secreted leptin, leading to tumor growth through leptin-mediated pathways. By in vitro assay, Juárez-Cruz et al. established that leptin promoted the secretion of the extracellular matrix remodelers, MMP-2 and MMP-9, and invasion in a FAK and Src-dependent manner, strongly suggesting that leptin promoted the development of a more aggressive invasive phenotype in mammary cancer cells (28). This result was similar to the study of Haque et al. that leptin could induce cell viability, epithelial-to-mesenchymal transition (EMT), sphere-forming ability, and migration of ER $\alpha+B C$ cell line (29). The effect was possibly mediated by inhibiting CCN5 signaling via activating JAK/AKT/STAT-pathway. Sabol et al. verified that obesity-altered adipose stem cells mediated EMT 
TABLE 1 | The roles of adipokines in linking obesity and BC.

\begin{tabular}{|c|c|}
\hline Adipokine & Model \\
\hline Leptin & $\begin{array}{l}\text { 3D cell coculture model (HMT-3522 S1 } \\
\text { mammary epithelial cells); DIO murine } \\
\text { model } \\
\text { Mammary epithelial cell models (HMEC, } \\
\text { MCF7 and MDA-MB-231) } \\
\text { Cultured cell model of BC (MCF7 and } \\
\text { MDA-MB-231) } \\
\text { Cultured cell model of BC (MCF-7, ZR- } \\
\text { 75-1 and MDA-MB-231) }\end{array}$ \\
\hline
\end{tabular}

Cultured cell model of BC (BT20, MDAMB-231, MDA-MB-468, MCF7 and HCC1806); TNBC PDX model Cultured cell model of BC (MCF7 and MDA-MB-231)

Cultured cell model of BC (E-Wnt, MWnt and MDA-MB-231); DIO MMTVWnt-1 transgenic murine model Co-culture model

Cultured cell model of BC (4T1); DIO murine BC model (4T1); human TNBC patients

Cultured cell model of BC (Py8119); DIO murine BC model (Py8119)

DIO murine BC model (4T1)

Cultured cell model of BC (MDA-MB231, BT-20, MCF7 and MDA-361)

Cultured cell model of BC (MCF-7 and SK-BR-3)

Co-cultured cell model of BC (MCF-7 and MDA-MB-231); murine BC model (MCF-7 and MDA-MB-231)

Adiponectin Murine BC model

Cultured cell model of BC (MCF-7 and MDA-MB-231); murine BC model (MCF7 and MDA-MB-231)

Obese $\mathrm{BC}$ patients

Obese BC patients

Resistin $\quad B C$ patients

Cultured cell model of BC (T47D, MCF-7 and MDA-MB-231) Cultured cell model of BC (MCF-7, MDA- Resistin could promote BC metastasis. MB-231 and MCF-10A)

Cultured cell model of BC (MCF7, T47D, Resistin could facilitate BC progression by

ZR-75-1, MDA-MB-231 and Hs-578 T); induction of EMT and stemness properties murine BC model (MDA-MB-231); zebrafish model
Leptin could promote BC initiation.

Leptin could modulate the oxidative status of BC.

Leptin could promote BC migration and invasion.

Leptin could induce BC motility, migration and invasion.

Leptin could induce BC migration and metastasis.

Leptin could encapsulate in EVs induced $\mathrm{BC}$ proliferation, migration and invasion.

Leptin could induce BC viability, migration, invasion, CSC enrichment and EMT.

Leptin could induce a pro-angiogenic effect on BC.

Leptin could induce BC progression and metastasis.

Leptin could increase the oxidation of fatty acids and $\mathrm{BC}$ progression.

Leptin could promote BC progression.

Leptin could promote $\mathrm{BC}$ resistance to immune attacks.

Leptin could promote bone metastasis of BC.

Leptin could promote BC growth and progression.

Adiponectin could accelerate the BC recurrence.

Adiponectin could inhibit ER $\alpha-B C$ growth and progression.

There was an association between adiponectin gene polymorphism, serum adiponectin level, and $\mathrm{BC}$ risk in obese postmenopausal women.

Polymorphism and promoter methylation of NA the adiponectin gene were associated with $\mathrm{BC}$ risk in obesity.

Resistin might be a predictive marker in BC NA treatment. NA

NA
Mechanism

Ref.

Leptin mediated the loss of apical polarity and promoted premalignant alterations of the mammary gland by activation of PI3K/Akt signals.

Leptin modulated the oxidative status of mammary epithelial cells differently according to their neoplastic state. Leptin induced cell migration and invasion in a FAK-Srcdependent manner in BC cells.

Leptin induced cell viability, EMT, sphere-forming ability, and migration of $E R \alpha+B C$ cells which was mediated by inhibiting CCN5 signaling via activating JAK/AKT/STATpathway.

Leptin produced by obASCs mediated EMT in vitro and promoted tumor metastasis in vivo.

leptin encapsulated in EVs derived from obese adipose tissue, thereby mediating pro-tumoral activities and malignancy phenotype of BC cells.

Increased leptin signaling was causally linked to obesityassociated TNBC development by promoting CSC enrichment and EMT.

VEGFA was up-regulated in macrophages after exposure to adipocytes through releasing leptin.

The leptin gene expression was negatively correlated with the infiltration of tumor-reactive CD8+ T cells in human TNBC tumors from obese patients when compared to non-obese.

Leptin-enriched mammary adipocytes and fat tissues downregulated CD8+ T cell effector functions through activating STAT3-FAO and inhibiting glycolysis. Leptin facilitated the MDSCs accumulation, while MDSCs down-regulated the leptin production. HFD-induced MDSCs participated in tumor growth facilitation by inhibiting lethal CD8+ T cells.

Leptin could drive the tumor to escape from immune attacks by enhancing fatty acid oxidation and tumor resistance to NK cell lysis via PGC-1 activation. Leptin promoted bone metastasis of $\mathrm{BC}$ by activating the SDF-1/CXCR4 axis.

The absence of leptin receptor modified BC phenotype less aggressive in vitro and reduced the macrophage recruitment in vivo.

Adiponectin played an inhibitory effect on the growth and progression of $\mathrm{ER} \alpha-\mathrm{BC}$ cells in vitro and in vivo

Resistin induced BC cells EMT and stemness through both CAP1-dependent and CAP1-independent mechanisms. Resistin facilitated BC progression via TLR4-mediated induction of mesenchymal phenotypes and stemness properties. 
TABLE 1 | Continued

\begin{tabular}{|c|c|c|c|c|}
\hline Adipokine & Model & Function & Mechanism & Ref. \\
\hline Visfatin & $\begin{array}{l}\text { Cultured cell model of BC (MCF-7 and } \\
\text { MDA-MB-231) }\end{array}$ & $\begin{array}{l}\text { Visfatin could induce BC proliferation and } \\
\text { inhibit apoptosis. }\end{array}$ & $\begin{array}{l}\text { Extracellular Visfatin induced proliferation through ERK1/2 } \\
\text { and AKT and inhibited apoptosis in BC cells. }\end{array}$ & $(48)$ \\
\hline SFRP5 & $\begin{array}{l}\text { Co-cultured cell model of BC (MCF-7 } \\
\text { and MDA-MB-231) }\end{array}$ & $\begin{array}{l}\text { SFRP5 could inhibit BC migration and } \\
\text { invasion. }\end{array}$ & $\begin{array}{l}\text { Adipocyte-derived SFRP5 inhibited BC cell migration and } \\
\text { invasion through Wnt and EMT signaling pathways. }\end{array}$ & (49) \\
\hline
\end{tabular}

DIO, diet-induced obesity; BC, breast cancer; EMT, epithelial-to-mesenchymal transition; obASCs, obesity-altered adipose stem cells; PDX, patient-derived xenograft; TNBC, triplenegative breast cancer; EVs, extracellular vesicles; CSC, cancer stem cell; VEGFA, vascular endothelial growth factor A; CAP1, cyclase-associated protein 1; SFRP5, secreted frizzledrelated protein 5; MDSCs, myeloid-derived suppressor cells; NA, not applicable.

in vitro and promoted the tumor metastasis of the TNBC patient-derived xenograft (PDX) model (30). Leptin produced by obesity-altered adipose stem cells (obASCs) is a key factor for mediating tumor metastasis. Notably, leptin could be encapsulated in extracellular vesicles derived from obese adipose tissue, thereby mediating pro-tumoral activities and the malignancy phenotype of $\mathrm{BC}$ cells (31). It was confirmed that diet-induced obesity (DIO) mice exhibited reduced survival, increased systemic metabolic and inflammatory disorders, upregulated tumoral cancer stem cell (CSC)/EMT gene signature, and greater leptin signaling (32). In cell culture experiments, leptin enhanced mammosphere formation, and the pro-cancer effects including cell viability, migration, invasion, and CSC- and EMT-related gene expression. Upregulation of leptin signaling could form a causal relationship with obesity-associated TNBC development by promoting CSC enrichment and EMT.

Leptin can directly remodel the TME by inducing metabolic changes in tumor cells and recruiting immune cells such as macrophages, CD8+ T cells, and myeloid-derived suppressor cells (MDSCs), which are capable of producing proinflammatory cytokines to maintain angiogenesis and tumor growth (51). Yadav et al. proved that VEGFA was up-regulated in macrophages after exposure to adipocytes through releasing leptin, representing a possible mechanism for the increased risk of $\mathrm{BC}$ progression in obese individuals (33). Evangelista et al. investigated the gene expression of leptin was negatively correlated with the infiltration of tumor-reactive CD8+ T cells in human TNBC tumors from obese patients when compared to non-obese (34). Besides, It was noticed that leptin could downregulate $\mathrm{CD} 8+\mathrm{T}$ cell functions through activating STAT3-fatty acid $\beta$-oxidation (FAO) and inhibiting glycolysis in obese mice fed on a high-fat diet (HFD) (35). On the other hand, HFD-induced MDSCs participated in tumor growth facilitation by inhibiting lethal CD8 $+\mathrm{T}$ cells (36). This was involved in the complicated crosstalk that leptin facilitated the myeloid-derived suppressor cells (MDSCs) accumulation, while MDSCs down-regulated the leptin production. Leptin could also drive the tumor to escape from immune attacks by enhancing fatty acid oxidation and tumor resistance to NK cell lysis via PGC-1 activation, thus showing a therapeutic clue for BC by blocking leptin (37). Duan et al. indicated that higher leptin receptor expression was related to increased malignancy and bone metastasis incidence in BC patients (38). The following in vitro assay further confirmed the role of leptin in promoting $\mathrm{BC}$ cell migration and invasion, via the SDF-1/CXCR4 axis activated by leptin. The absence of leptin receptor modified BC phenotype less aggressive in vitro and reduced the macrophage recruitment in vivo, proposing an innovative role of leptin receptor in modulating BC features (39).

Overall, leptin is emerging as the most important molecular mediator of the obesity-BC axis. The overactive leptin network interacts with $\mathrm{BC}$ cells directly or with different components in TME indirectly, thus participating in multiple steps of $\mathrm{BC}$ initiation and progression. Totally, the therapy targeting leptin deserves a deep evaluation in $\mathrm{BC}$ risk control and management for improving clinical outcomes and reducing mortality.

\section{Adiponectin}

Another adipokine that plays a critical role in obesity-associated $\mathrm{BC}$ is adiponectin with a molecular weight of $28-30 \mathrm{kDa}$, which is mainly secreted by adipocytes (52). There has been sufficient literature to prove the important role of adiponectin in the pathogenesis of obesity-related diseases (52). Ecker et al. observed that serum levels of adiponectin decreased in a dietinduced obese mouse model, which was negatively correlated with obesity and accelerated the BC recurrence (40). Mauro et al. certified the inhibitory effect of adiponectin on the growth and progression of $\mathrm{ER} \alpha-\mathrm{BC}$ cells in vitro and in vivo. While in $\mathrm{ER} \alpha+$ BC cells, low adiponectin levels, similar to the circulating concentration of adiponectin in obese women, acted as a stimulator for their growth and progression (41). Based on the above observations, higher doses of adiponectin and an appropriate combination of anti-estrogen therapy should be administered for $\mathrm{ER} \alpha+\mathrm{BC}$ obese patients.

There are a variety of single-nucleotide polymorphisms in the adiponectin gene. Mahmoud et al. confirmed that there was an association between adiponectin gene polymorphism, serum adiponectin level, and the risk of $\mathrm{BC}$ in obese and overweight postmenopausal women (42). Besides, Pasha et al. simultaneously studied the genetic and epigenetic changes of the serum level of adiponectin gene and uncovered that polymorphism and promoter methylation of the adiponectin gene were associated with BC risk in obesity (43). A new noninvasive biomarker designed by evaluating the methylation status of the adiponectin gene promoter can be produced and used as an encouraging tool for early detection of BC.

Decreasing levels of adiponectin in the obese woman may reduce the beneficial effects of adiponectin on BC, including inhibiting BC cell proliferation or stimulating apoptosis of $\mathrm{BC}$ cells. Novel therapeutic approaches toward adiponectin could be 
of great significance in the prevention or treatment of $\mathrm{BC}$ for obese women.

\section{Resistin}

Resistin, a $12.5 \mathrm{kDa}$ protein encoded by the RETN gene, is related to obesity, inflammation, and various cancer type, including BC. Based on the anthropometric data and parameters, Patrício et al. indicated that resistin and glucose, as well as age and BMI, could be used as a powerful biomarker of BC (53). Wang et al. identified high levels of resistin in $\mathrm{BC}$ patients in Chinese Han women, and resistin might be a predictive marker in $\mathrm{BC}$ treatment (44). They also proved the association between polymorphisms of the RETN gene and susceptibility for BC.

Growing evidence has indicated that resistin is upregulated in $\mathrm{BC}$ patients, yet the mechanisms of resistin on adjusting $\mathrm{BC}$ behavior during obesity are still largely unknown. Rosendahl et al. suggested that resistin significantly stimulated both ER $\alpha+$ $\mathrm{BC}$ and TNBC cell progression by utilizing the most extensively used adipocyte model in vitro, which could be further strengthened under obesity-related metabolic conditions (45). CAP1, as a newly identified resistin receptor, was expressed across a large panel of BC cell lines and primary BC tumors, and high expression of CAP1 was associated with poorer tumor characteristics, higher histological grades, and impaired prognosis among $\mathrm{BC}$ patients, highlighting the potential role of CAP1 concerning BC outcome. Besides, Avtanski et al. pointed out that adipokine resistin could enhance the metastatic potential of BC cells via inducing EMT and stemness in vitro, partially mediating by CAP1 (46). Similarly, Wang et al. observed that high expression of serum resistin in BC patients was positively associated with tumor stage, size, lymph node metastasis, and poor patient survival (47). Their study verified that obesity-related resistin facilitated BC progression by induction of EMT and stemness properties of BC cells via activating TLR4/NF- $\kappa \mathrm{B} / \mathrm{STAT} 3$ signaling in animal models of $\mathrm{BC}$ tumorigenesis and metastasis. Gao et al. confirmed that obesity elevated the expression of adipocytic TAZ/Resistin (a functional downstream target of TAZ), and facilitated tumorigenesis in vitro and in vivo. They also found that the resistin expression was strongly related to adipocytic TAZ and advanced clinical stage in TNBC samples (54).

\section{Other Adipokines}

Visfatin is an adipokine and proinflammatory cytokine secreted by adipocytes, macrophages, and inflamed endothelial tissue and is dramatically increased in obese BC patients. Elevated levels of visfatin may promote the development of $\mathrm{BC}$ and reduce the effectiveness of treatment in BC patients (48). Gholinejad et al. discovered that Extracellular Visfatin induces BC cell proliferation through activation of the AKT/PI3K and ERK/ MAPK signaling pathways and inhibits apoptosis in these BC cells (48). The role of visfatin in the development of BC further confirms the relationship between obesity and BC.

SFRP5 is a novel adipokine with anti-inflammatory properties and is related to obesity. The plasma level of SFRP5 is significantly reduced in obese patients and SFRP5 expression is also decreased in various tumor tissues (49). Zhou et al. revealed that in BC patients, SFRP5 is negatively correlated with BMI, lymph node metastasis, infiltration, TNM stage and higher Ki67 expression, and elevated SFRP5 levels were connected with the improved prognosis of BC patients (49). In addition, they detected reduced SFRP5 level in the obesity-induced hypertrophic adipocyte model, and the hypertrophic adipocytes augment BC cell invasion and migration through inhibiting SFRP5 expression. The promotion effect of hypertrophic adipocytes was reversed by the addition of SFRP5 via downregulating Wnt and EMT signaling pathways. SFRP5 is a vital adipokine that could mediate the crosstalk between obesity and BC metastasis and new therapy by promoting SFRP5 expression in the adipose microenvironment might be an effective way in preventing BC metastasis.

\section{Insulin and IGF}

In obesity, the expansion of adipose tissue can lead to a chronic inflammatory state contributing to the elevated levels of circulating insulin, IGF, and obesity-related insulin resistance, thus creating a more favorable TME for carcinogenesis (4). Hyperinsulinemia has become a research hotspot as a potential mediator for the growth of obesity-related BC, and the increased plasma levels of insulin independently predict the increased risk and mortality in obesity-related tumors, including BC and several other tumor types $(17,55)$ Obesity-related hyperinsulinemia could lead to the abnormal insulin signaling pathway, which may affect the expression and localization of insulin receptor (InsR), in BC (56). According to the study by Swedish scholars, obese patients with nuclear InsR-/ER- had the worst prognosis of all 900 patients with primary invasive BC (57).

Insulin can act synergistically with inflammation to promote $\mathrm{BC}$ growth and metastasis (58). Insulin could increase the expression of VEGFA in macrophages and have proangiogenic effects in vitro endothelial tube formation assay (33). Rabin-Court et al. validated that the obesity-driven elevated insulin could upregulate mitochondrial glucose oxidation in obesity-associated tumor cell lines (BC, colon cancer, and prostate cancer cells) correlated with a dosedependent increase in cell division (59). RodriguezMonterrosas et al. proposed that insulin, by activating insulinlike growth factor 1 (IGF-1) receptor, induced the proliferation, migration, invasion, and an enhanced MMP-9 secretion in MDA-MB-231 cells pretreated with linoleic acid in vitro, strongly suggesting the important role of insulin signaling in $\mathrm{BC}$ invasion and metastasis (60). Insulin resistance, associated with hyperinsulinemia, hypertension, and impaired glucose tolerance, has been considered as the underlying cause of the relationship between obesity and high BC risk, prognosis, and survival. Through the more accurate assessment and appropriate stratification of patients by BMI and menopausal status in a prospective study, Luque et al. revealed a clear association between BC presence and higher insulin resistance in overweight/obese premenopausal women (61).

IGF-1 is an insulin-related hormone that is involved in a variety of physiological and pathological processes, including cell proliferation and differentiation, tumor growth, and metastasis. 
IGF-1 has been indicated as an endocrine BC risk factor. Ecker et al. utilized a genetically engineered mouse model that outlined the physiological characteristics of obese patients and showed that HFD obese mice exhibited hyperinsulinemia, increased IGF1 levels, and accelerated BC recurrence when compared with the control mice, suggesting that the insulin/IGF-1 signaling pathway is a potential mediator of the relationship between obesity and BC recurrence (40). Tong et al. found that high IGF-1 was related to an impaired 4-year recurrence-free survival (RFS) for overweight patients in a retrospective study of HER2+ $\mathrm{BC}$ patients (62). It was the first and largest study to prove the significant interaction between IGF-1 and BMI in predicting RFS and $\mathrm{OS}$ in HER2+ BC patients. Hillers et al. injected the mixed adipocyte-derived stem cells (ASCs) which were isolated from HFD fed mice or the control diet with BC cells into the mammary glands of lean mice and observed that obese mouse ASCs induced an invasive phenotype of BC cells by increasing the expression of IGF-1 (63).

Thus, obesity is recognized to be a state of chronic inflammation characterized by elevated circulating levels of pro-inflammatory mediators, including IL-6, C-reactive protein (CRP), CC chemokine ligand 2 (CCL2), TNF- $\alpha$, and disordered non-coding RNA, which function in the $\mathrm{BC}$ cell proliferation, invasion, and migration in a paracrine manner. Meanwhile, inflammation is a common symptom in both obesity and BC and acts as a direct bridge between the two. Besides, the inflammation milieu can even interact and collaborate with hyperglycemia, adipokines, hormone-associated aromatase alteration, thus creating an extraordinarily complex obesityinflammation axis for supporting BC progression. Novel therapeutic interventions targeting and controlling inflammation would be of great value in obesity-related BC.

\section{Sex Hormone}

Most of the BC are hormone-dependent tumors, and the increased exposure to sex hormones may facilitate the development of BC. It was reported that elevated steroid hormone levels in obesity increased the mortality in hormone receptor-positive BC patients (64). In addition, increased estrogen levels were associated with obesity and independently correlated with an elevated risk of BC (65). Adipose tissue converts androstenedione to estrone by aromatase of stromal cells to produce estrogen after menopause. A randomized, placebo-controlled trial confirmed that the expression of aromatase, the rate-limiting enzyme in estrogen biosynthesis, was increased in the breast tissue of obese patients, which led to an elevated risk of $\mathrm{HR}+\mathrm{BC}$ in obese postmenopausal women and docosahexaenoic acid could reduce the expression of aromatase (66). Subbaramaiah et al. pointed out that prostaglandin E2 down-regulated sirtuin1 leading to an increase of aromatase in breast tissues of obese women, providing novel insights into the obesity-BC connection (67).

Sabol et al. showed that obASCs promoted ER+ BC tumor growth through estrogen signaling in vivo, while for metastasis, the promotion effect of obASCs was not entirely estrogendependent (68). Zhao et al. found that in the breast tissue of premenopausal obese women, the expression of genes related to estrogen (such as ESR1 and GATA3) and genes involved in cell growth and protein synthesis (such as RPS6KB1) was significantly reduced in breast tissue. In postmenopausal obese women, the inflammatory molecule PTGS2, ESR1 target gene TFF1, and cell cycle G1/S checkpoint gene CCND1 were elevated (69). The differential expression of these genes may help to explain the difference in BC-promoting effects of estrogen in obese women according to menopausal status. Qureshi et al. showed that the postmenopausal estrone and premenopausal $17 \beta$-estradiol played opposing roles in BC-promoting effects of obesity. Estrone is pro-inflammatory in contrast to the antiinflammatory actions of $17 \beta$-estradiol and increases with obesity, and stimulates the expansion of tumor-initiating stem-like cells in $\mathrm{ER}+\mathrm{BC}$ to drive rapid $\mathrm{BC}$ growth in vivo (70). Understanding the hormonal environment in tumor tissue may be crucial to elucidating the $\mathrm{BC}$ etiology and improving patient outcomes.

The excessive fat accumulation, chronic low-grade inflammation, and numerous pro- and anti-inflammatory factors caused by obesity are closely related to elevated estrogen/aromatase expression and activity in post-menopausal women (71). These changes are determined as the underlying force of obesity in promoting the occurrence of postmenopausal BC (72). In general, aromatase and estrogen may still be key factors in the link between obesity and poor prognosis in ER $\alpha$ positive, post-menopausal BC patients. The aromatase overexpression in dysfunctional obesity states indicates its potential pharmacologic target for BC prevention.

As important inflammatory mediators, interleukin (IL)-6, tumor necrosis factor (TNF)- $\alpha$, CCL2, cyclooxygenase-2 (COX-2), and prostaglandin E2 (PGE2) catalyzed from COX-2 participate in the induction of aromatase expression in breast adipose tissue. In obese mice and subcutaneous adipose tissue from obese women, CCL2 was increased in breast adipose tissue and enhanced the glucocorticoid-mediated CYP19A1 transcription, thus promoting the pro-inflammatory milieu and aromatase expression under obesity condition (73). Hypoxiainducible factor $1 \alpha(\mathrm{HIF}-1 \alpha)$ was a dominant regulator of oxygen homeostasis and could stimulate aromatase and CREB1 expression in response to tumor-derived and obesity-associated pro-inflammatory mediator PGE2 (74). Zahid et al. supported that the obesity-associated increased the aromatase expression in human breast tissue, at least partially due to the increased in situ expression of aromatase (75). They also confirmed the involved mechanism by which leptin could regulate aromatase via the activation of the p53-HIF-1 $\alpha /$ PKM2 axis. TNF- $\alpha$ was a key driver of aromatase gene expression. Obesity was related to the enhanced TNF- $\alpha$ and reduction in local IL-10, which mediated the aromatase and estrogen biosynthesis in mammary adipose tissue, providing novel insight for prevention strategy of postmenopausal obesity-associated BC (76).

In the mammary gland and visceral fat of obese mice, the increase of aromatase mRNA and activity was paralleled with the increase of TNF- $\alpha$, IL- $1 \beta$, and COX-2. These pro-inflammatory mediators in turn promoted the induction of aromatase (77). The increase in fat mass and aromatase may be responsible for the 
increased risk of $\mathrm{HR}+\mathrm{BC}$ in postmenopausal obese women. High-sugar/fat diet increased the levels of pro-inflammatory mediators CCL2, IL-6, COX-2, and PGE2 in breast tissue, accompanied by the formation of breast coronal structure and the up-regulated biosynthesis of aromatase/estrogen (78). It showed that the obesogenic diet accelerated BC carcinogenesis in a COX-2-dependent manner. By in vitro verification, Bowers et al. showed that obesity-induced systemic IL-6 indirectly increased the aromatase expression derived from pre-adipocyte through augmented BC cell PGE2 production, which resulted in a subsequent increase in BC cell ER $\alpha$ activity and proliferation (79). It suggested that obesity IL- 6 might be a potential mechanism to enhance the postmenopausal, hormone-responsive $\mathrm{BC}$ progression via an elevated local aromatase expression.

Therefore, local production of inflammatory mediators surrounding adipose tissue and in the tumor, and estrogen increase, which is thought to establish a carcinogenesispromoting microenvironment and further drive tumor growth by significantly increasing the role of aromatase. Obesity-related aromatase increases in adipose tissue and the whole body system, while hormone therapy lifestyle interventions including weight management and may reduce $\mathrm{BC}$ risk by decreasing levels of related hormones and aromatase.

\section{Chronic Inflammation}

The relationship between obesity and $\mathrm{BC}$ is ascribed to diverse factors, while the chronic low-grade inflammation accompanied by obesity is the closest link between them. Recently, the significant role of white adipose tissue (WAT) inflammation in the progression and metastasis of obesity-related BC has been gradually recognized $(66,80)$. The results of a retrospective study showed that breast WAT inflammation is usually generated in overweight/obese BC women and may be related to abnormal circulatory indicators related to metabolic syndrome (81). Previous studies have confirmed the systemically BC promotion effect of adipose inflammation via circulating pro-inflammatory cytokines, such as IL-6 and TNF- $\alpha$ (82). Since BC is located in a fat-rich environment, recent studies have mainly focused on the local effects of inflamed adipose tissue, including the impact of cytokine levels in mammary adipose tissue on BC (83). A study of Australian scholars indicated that obesity reduced the local IL-10 level in the mammary fat pad of ovariectomized mice, and the reduced IL-10 enhanced the expression of aromatase in mammary fad in ovariectomized mice, contributing to $\mathrm{BC}$ development and progression (76).

In obesity, breast adipose tissue induces inflammation by increasing the expression of pro-inflammatory cytokines and the recruitment of macrophages, and the elevated pro-inflammatory cytokines, in turn, upregulated genes and signaling pathways that contribute to breast inflammation and BC progression $(84,85)$. Notably, the crown-like structures (CLSs), constituted by necrotic and dying adipocytes encircled by macrophages in adipose microenvironments, are a histologic hallmark for the proinflammatory process (86). Studies have shown that the CLSs of the breast are more frequently detected among obese compared to non-obese BC patients and high CLS-densities are independently associated with an increased BC risk (87). CLS-related proinflammatory behaviors are believed to increase the risk of worse BC prognosis in obese or post-menopausal patients. As confirmed by Maliniak et al., there was an intensive positive association between BMI and CLSs from breast adipose tissue in non-tumor tissue, which was independent of race (87). Importantly, the adipocyte-macrophage crosstalk in obesityrelated $\mathrm{BC}$ mainly involves excessive inflammatory cytokines secretion (TNF- $\alpha$, IL-1 $\beta$, IL-6, and PGE2), TSC1-TSC2 complex-mTOR, insulin resistance, endoplasmic reticulum stress, and increased levels of aromatase activity and estrogen production. For instance, in both dietary and genetic models of obesity, Subbaramaiah et al. proved observed the presence of CLSs with a typical structural feature, which was related to NF-kB activation, increased pro-inflammatory cytokines, and the elevated expression and activity of aromatase in the mammary gland (77). Moreover, large epidemiologic studies have demonstrated that obesity positively contributes to the formation of CLSs and their association with clinical BC outcomes (88). Therefore, targeting CLSs in breast adipose tissue emerges as a prominent therapeutic strategy, and the tests of body adipose tissue composition and inhibition of inflammation state will be of value to direct combinatorial approaches.

Wilcz-Villega et al. proved that conditioned medium of macrophages derived from human healthy donors facilitated the acquisition of malignant traits (such as anchorageindependent growth and invasiveness) in mammary epithelial cells in 3D culture, which was mediated by IKKe/TBK1 kinases and the serine biosynthesis pathway (89). Tiwari et al. proposed a pro-inflammatory metabolically activated phenotype (MMe) macrophage reprogrammed by obesity that could promote tumorigenesis, which is different from the pro-inflammatory M1 macrophage that antagonized tumorigenesis (90). They showed that MMe macrophages represented the main macrophage phenotype in mammary fat of obese women and mice. MMe macrophages secreted IL-6 in a NOX2-dependent manner through combining with GP130 on TNBC cells to promote stem-like properties and tumorigenesis during obesity. Besides, Kolb et al. identified that obesity increased tumor-infiltrating macrophages with NLRC4/IL-1 $\beta$-dependent upregulation of angiopoietin-like 4, contributing to increased angiogenesis and BC progression in the obese mouse tumor (91).

The influence of obesity-induced inflammation and hormone production on tumorigenesis is determined by the menopausal status. Cranford et al. found that HFD induced inflammation was correlated with increased tumorigenesis in an ovariectomized mouse model of premenopausal hormone receptor-positive BC, but had no significant effect in postmenopausal mice (92). Certain micro-RNAs (miRs) that participated in the regulation of inflammation are known as inflamma-miRs. A cohort study of Tunisian patients reported that chronic inflammation in obese BC patients was associated with aggressive BC by inducing overexpression of oncomiRs (such as miR-21 and miR146a) and reducing the expression of tumor suppressor miRs (such as miR34a) (93). More comprehensive mechanism studies connecting obesity-driven inflammation with $\mathrm{BC}$ are needed for more 
potential therapeutic strategies of BC. In total, obesity often leads to insulin resistance, which can cause compensatory hyperinsulinemia. Adipocyte dysfunction in the context of obesity is the basis of insulin resistance and chronic inflammation, which can lead to the development and progression of $\mathrm{BC}$. Moreover, the cross binding of insulin to the IGF-1 receptor expressed on $\mathrm{BC}$ cells stimulates the proliferation of BC cells. Therefore, insulin and IGF-1 have been identified as $\mathrm{BC}$ promoters that activate many pathways that drive aggressive $\mathrm{BC}$ biology. The favorable insulin signaling control will optimize $\mathrm{BC}$ risk prevention and $\mathrm{BC}$ survival.

\section{THE EVOLVING ROLE OF OBESITY IN BREAST CANCER THERAPY}

\section{Surgery}

Generally, obesity is thought to be a risk factor in surgery procedures due to the increased incidence of complications. Patients with obesity are at increased risk of developing complications of varying degrees [such as infection $(94,95)$ seroma formation (96), lymphedema (97), flap thrombosis/necrosis (98), and delayed breast cellulitis (99)] after mastectomy alone or in combination with autologous/implant-based immediate breast reconstruction (100). Garland et al. indicated that increasing obesity progressively increased the postoperative complication rates even without $\mathrm{BC}$ reconstruction (101). Obesity is indispensable information of preoperative consultation and appropriate risk stratification for BC patients. Most of the surviving patients who undergoing BC surgery suffer from persistent pain, which greatly reduced their quality of life. Ding et al. reported that BMI might be positively correlated with the risk of persistent pain after BC surgery (102).

With the rising prevalence of obesity, breast reconstruction in obese patients is becoming the norm rather than the exception nowadays. In plastic surgery studies comparing autologous and prosthetic reconstruction between obese and nonobese patients, it found an increased complication rate and a decreased satisfaction rate in the obese group (103). Consistently, in a retrospective study, the obese patients with BC reconstruction after mastectomy exhibited increased complications and failure rates compared with the normal population, while reconstruction with free tissue transfer from the abdomen presented more satisfactory outcomes and decreased complications than prosthetic reconstruction (103). Chang et al. also proved the safety of autologous breast reconstruction in obese patients (104). These results meant that obesity was not contraindicant and might be an excellent option for reconstruction in obese patients. For obese women with surgical risk factors for prosthetic breast reconstruction, surgical modification can also reduce the occurrence of perioperative complications (105). Therefore, the personalized assessment of preoperative risk, intraoperative techniques, and postoperative management are essential to maximize prognosis and reduce complications for obese patients.

\section{Radiotherapy}

Post-surgery adjuvant RT significantly reduces the local recurrence rate and ameliorates the clinical outcomes of $\mathrm{BC}$ patients. RT-caused adverse responses, mainly including skin toxicity, pain, lymphedema, and telangiectasia, are caused by RT damage to the surrounding normal tissue and negatively impact the overall quality of patient life. Cutaneous inflammation and toxicity may be a major source of RT-related pain in BC patients. The inflammatory biomarker CRP is an indicator of RT-related pain in BC patients. Intriguingly, Lee et al. firstly proposed that obesity was a correlative factor, as more increased risk of RTrelated pain appeared in obese patients (pre-RT CRP $\geq 10 \mathrm{mg} / \mathrm{L}$ ) than those non-obese patients (pre-RT CRP $<10 \mathrm{mg} / \mathrm{L}$ ) (106). In $\mathrm{BC}$ patients with RT therapy, $\mathrm{Hu}$ et al. also pointed out the risk of obesity-related to Grade 4+ skin toxicity and other late effects (107). Obesity-induced metabolism abnormalities are crucial for aggravating RT resistance and poor prognosis of $\mathrm{BC}$. In a retrospective study with $\mathrm{BMBC}$ patients treated with $\mathrm{RT}$, McCall et al. confirmed that BMI negatively affected OS and local control, showing the significance of BMI for prognosis and clinical trial design by using as a stratification (108). The in vitro assay of Sabol et al. evaluated the effects of obesity-altered ASCs on ER+ BC cell response to RT (109). They concluded that obesity could alter the ASCs phenotype to confer undesired RT resistance via enhanced secretion of leptin by ASCs, promoted the production of IL-6, and activated Notch pathways in these BC cells. Thus, it posed evidence of obesity-related paracrine effect in shaping obese BC prognosis.

\section{Chemotherapy}

Emerging clinical studies have shown that obesity is able to hurt chemotherapy efficacy, leading to a reduced likelihood of achieving pathological complete response (pCR) in obese and overweight patients. Interestingly, multi-agent regimens also enhance the risk of gaining weight during chemotherapy, and this weight gain might reduce the effectiveness of treatment. Obesity-mediated drug resistance can be achieved by altering drug pharmacokinetics, formulating chronic inflammation, and promoting tumor-related adipocyte adipokine secretion (110). By using a co-culture system to grow BC cells with primary mammary adipocytes isolated from lean and obese patients, Lehuédé et al. found that these human mammary adipocytes induced chemoresistance in BC cells, which was amplified by obesity (111). Adipocytes induced a multidrug-resistant phenotype in $\mathrm{BC}$ cells, as the level of major vault protein was increased to promote doxorubicin (DOX) nuclear efflux. Liu et al. showed that resistin treatment could induce autophagy to decrease the DOX-induced BC cell apoptosis in vitro, suggesting that upregulated levels of resistin conferred DOX resistance in BC therapy (112). Therefore, targeting resistin might be a novel strategy to improve chemoresistance. Mentoor et al. found that DIO weakened the DOX efficacy in a breast tumor-bearing mouse model (113). They found that both the expression level of leptin and resistin were significantly increased in the HFD group treated with DOX, confirming obesity conditions induced the changes in tissue fatty acid composition to further reduce the therapeutic effect of DOX.

Obesity is also associated with some side effects of chemotherapy. For young BC patients before menopause, adjuvant chemotherapy may cause interrupted menstruation and premature menopause, 
which may damage their life quality. Yeo et al. led a study of 280 young Chinese women with premenopausal BC who received adjuvant chemotherapy for 3 to 10 years, concluding that overweight/obesity was associated with more severe menopausal symptoms (114). To determine the relationship between obese BC patients and febrile neutropenia, Collins et al. conducted a singlecenter, retrospective chart review (115). The results indicated that obese patients had no increased risk of febrile neutropenia, but the threshold for febrile neutropenia was lower and required more antibiotics after chemotherapy. It is worth noting that up to $90 \%$ of $\mathrm{BC}$ patients experience cancer-related fatigue (CRF), which is considered the most durable and painful physical injury after treatment. Inglis et al. evaluated the obesity impact on CRF in BC patients and found that obese patients underwent higher CRF from before chemotherapy to 6 months after chemotherapy (116). Active measures related to weight loss interventions and diet changes may improve the CRF degrees of obese BC patients pre- and post-chemotherapy.

Aldo-keto reductase (AKR) is a supergene family which comprises 14 families and more than 40 members. AKR enzymes are $\mathrm{NADPH}$-dependent oxidoreductases that can interconvert carbonyl groups with alcohols. But recent studies have shown that AKR1 takes part in the malignant transformation of some human tumors, such as BC, and as well as in the resistance to cancer treatment (1). AKR1C3, belonging to the AKR family, may play an important role in the development of hormone-dependent or hormone-independent BC. It is known that AKR1C3 is abundantly expressed in $\mathrm{BC}$ and is associated with a worse prognosis. AKR1C3 is also related to DOX resistance in human BC (2). Byrns et al. confirmed that the expression of AKR1C3 in MCF-7 cells resulted in the elevated ratio of $17 \beta$-estradiol: progesterone, conferring a proliferative preponderance to $\mathrm{BC}$ cells (3). AKR and carbonyl reductases (CBR) enzymes can metabolize a variety of drugs and obese individuals can express high levels of these enzymes. It seems that AKR and CBR enzymes might play an important role in obesity-induced BC drug resistance. Sheng et al. demonstrated that obesity was associated with higher adipose tissue expression levels of AKR isoenzymes, including AKR1C1, AKR1C2, and AKR1C3, prompting the inactivation of anthracyclines, such as daunorubicin, by conducting mouse experiments and human tissue verification for the first time (4). These alterations may lead to the local reduction of efficacy of chemotherapy and result in $\mathrm{BC}$ chemotherapy resistance.

The effect of obesity on BC patients receiving neoadjuvant chemotherapy (NAC) is still a matter of debate. Some studies have shown that obese and overweight patients are less likely to achieve NAC pCR, while others have found no significant difference in pCR between obese and non-obese women. Karatas et al. assessed BMI and pCR to NAC and revealed that obesity was associated with lower pCR to NAC and lower OS, which may be caused by the reduction of therapeutic dose in this group of patients due to obesity-induced chemotherapeutic resistance (117). The NeoALTTO trial showed that obesity and overweight were associated with a decreased chance of HER2+ luminal BC patients obtaining pCR (118). Notably, there was no differential effect observed between BMI and pCR in HR- cases, leading to a statistically significant interaction between BMI and $\mathrm{HR}$ status. Obese $\mathrm{BC}$ patients are known to have a lower pCR rate, and more aggressive, dose-free chemotherapy combinations could be considered for better efficacy. Farr et al. retrospectively analyzed the obesity-related effects on pCR and survival (119). The main finding was that obese women who received a full unbounded dose of anthracycline-taxane-based NAC increased pCR and benefited progression-free survival, which might also lead to increased dose intensity associated with improved efficacy and toxicity. Méndez-Hernández analyzed the serum and tissue samples of primary $\mathrm{BC}$ patients in Mexican that received neoadjuvant therapy and confirmed that the polymorphisms of Leptin (LEP rs7799039) and adiponectin (ADIPOQ rs1501299) were risk-contributing factors in overweight/obesity patients (120). These genotypes influenced the response to chemotherapy, indicating that the obese microenvironment was more inclined to tumor progression and drug resistance by defining TME.

The American Society of Clinical Oncology (ASCO) clinical practice guidelines published a study on the appropriate chemotherapy dose for obese adult cancer patients in 2012 (121). Morrison et al. added the evidence supporting the use of actual weight-based dosages in accordance with the 2012 ASCO guideline for appropriate chemotherapy dosing, including in older cancer patients (122). Dose adjustment is a feasible strategy to potentially improve long-term survival in obese patients without increased toxicity. A prospective PANTHER study also showed that customized, dose-intensive epirubicin/cyclophosphamide and docetaxel were associated with improved BC relapse-free survival in obese patients compared to standard care, but not in non-obese patients (123). Natural phytochemicals can affect BC proliferation and metastasis signaling networks by regulating chronic inflammation related to excess, and sensitize the efficacy of chemotherapy drugs on BC cells (124). Some novel combinations of phytochemicals, developmental agents and/or chemotherapeutic agents will facilitate the achievement of effective solutions that expand and enhance multi-tiered intervention strategies for BC prevention and treatment. A series of further studies with a larger sample will enable us to better understand the dynamic changes of obesity to BC chemotherapy and other adjuvant treatments synergistically.

\section{Endocrine Therapy}

Since approximately $75 \%$ of $\mathrm{BC}$ express two hormone receptors; $\mathrm{ER}$ and/or PR, adjuvant ET is used in the treatment of most BC patients, including anti-estrogen therapy or suppression of estrogen production (125). The standard therapy for most ER+ $\mathrm{BC}$ patients includes selective ER modulators and aromatase inhibitors (AIs), which can counteract the tumorous on ER activity or suppress the adipose tissue to aromatize androgens into estrogen. Obesity increases the levels of circulating sex hormones, including estrogen, and is associated with a higher risk of ER+ BC and ET side effects. This will cause ET to be less effective in obese women with BC. AIs are the treatment of choice for some women with $\mathrm{ER}+\mathrm{BC}$, but there are reports that tamoxifen (Tx) may be more effective for obese women 
compared with AIs $(126,127)$. Zewenghiel et al. investigated the effect of BMI on ET efficacy in postmenopausal women with metastatic $\mathrm{HR}+\mathrm{BC}$ and showed that fulvestrant and AIs had no difference in the efficacy among normal, overweight, and obese women (128). Regarding the relationship between BMI and decreased efficacy of AIs, the existing results are still controversial. Obesity is associated with a reduced risk of fracture in healthy postmenopausal women, but for patients with early BC treated with AI, obesity may have the opposite effect. One possible mechanism for this was that AIs inhibited estrogen production, resulting in a loss of protection against fragility-related fractures (129). Obesity may become an additional parameter for clinical decisions to use bisphosphonates or denosumab to reduce fracture risk in ET patients with AI.

The mechanism of obesity in promoting ET resistance is complex and has been well concerned. In the athymic nude mice, the obesogenic diet could induce obesity, glucose tolerance, and hyperinsulinemia, and insulin resistance, which further mediated letrozole resistance. This effect might partially be attributed to the higher aromatase expression in the adipose tissue with obesity (130). In order to understand the mechanism of the weakened effect of ET on BC cells in the presence of the adipocyte secretome, mature adipocytes were co-cultured with BC cells and treated with ET (Tx, fulvestrant, Showing that the interplay between the adipocyte group and cells together played an important and complex role in ET resistance (131). Hagen et al. quantified non-adherence and discontinuation to ET in post-menopausal women with $\mathrm{BC}$ and found that overweight and obesity were time-dependent risk factors predictive for ET termination (125). Maintaining a normal BMI can improve ET compliance in postmenopausal women with BC. Wellberg et al. demonstrated that obesity and excess energy shaped a tumor environment characterized by ET resistance, and identified the participation of FGFR1 signaling in obesity-related BC progression (132). In the co-culture system of MCF7 cells and human adipocytes exposed to high Glucose, adipocyte-derived IL-8 mediated the enhanced connective tissue growth factor (CTGF) mRNA and reduced tamoxifen responsiveness of $\mathrm{BC}$ cells (133). Moreover, targeting IL-8 in the TME could not only reduce the inflammatory state but also indirectly modulate CTGF, thus improving the effectiveness of tamoxifen treatment in BC. Morgan et al. cultured the patient-derived stroma in an organotypic breast model in vitro and found that MCF7-derived ducts co-cultured with obese stromal cells possessed higher maximal aromatization-induced ER transactivation and reduced anastrozole sensitivity (134). This suggests that breast adipose stromal cells from obese women decrease AI sensitivity and supported obesity as a therapeutic for $\mathrm{ER}+\mathrm{BC}$ patients. Strong et al. suggested that ER+ BC cells were responsive to the obASCs with enhanced growth and EMT during direct coculture mode, whereas lnASCs were unable to increase ER+ $\mathrm{BC}$ growth (135). The mechanism validation showed the obASCderived leptin was a key molecule to drive BC tumorigenicity and potential ET therapy. More intriguingly, compare to normal control, the plasma exosomes from obese women significantly promoted the $\mathrm{BC}$ cell proliferation, migration, invasion, and resistance to tamoxifen, indicating that the obese circulating exosome was a potential mediator of adipose tissue involved in tamoxifen resistance.

Specific adipokines could reduce the efficacy of ET in the treatment of overweight/obesity. Bougaret et al. studied whether mature adipocytes and their secretions from adipose stem cells of normal-weight (MA20) or obese (MA30) women, could influence the effects of Tx (136). In a co-culture 3D model, the anti-proliferative effect of Tx on MCF-7 BC cells was counteracted by MA30. Besides, leptin, IL- 6 , and TNF- $\alpha$ could decrease the anti-proliferative efficacy of the active metabolite 4hydroxytamoxifen of Tx. Especially, it is worth noting that obesity-related leptin has been confirmed to interfere with the endocrine therapy outcomes in BC patients, such as tamoxifen. Obese patients secrete a large amount of leptin to exert proliferative, mitotic, anti-apoptotic, and pro-inflammatory activities, thus may have antagonistic effects on the treatment of Tx (137). For example, the in vitro leptin administration could result in promoted tamoxifen-resistance via leptin/Ob-Rb/ STAT3 pathway by regulating the apoptosis-related genes BCL2 and WWOX in HER2-overexpressing BC cells (138). Besides, Qian et al. found that leptin-mediated tamoxifen resistance of $\mathrm{BC}$ was correlated with the activation of ERK1/2 and STAT3 signaling and overexpression of cyclin D1 in MCF-7 BC cells by binding to ObRb (139). Similarly, Gelsomino et al. found a role of obesity-related leptin in sustaining AIs resistance that leptin signaling boosted the AIs resistant BC cell growth and macrophage activation (140). Therefore, the hyperactive leptin signaling network influences the $\mathrm{BC}$ through direct effects on tumor cells or indirect impacts on different components of the TME (141). This evidence highlights the clinical value of targeting leptin in improving the hormone therapy for $\mathrm{BC}$ in obese BC patients. In particular, identifying specific adipokine levels could help individualize the management of overweight BC patients. The efficacy of leptin-targeted drugs deserves in-depth exploration in the individualized management of overweight BC patients to improve clinical outcomes and decrease mortality. Furthermore, because obesity loses an equilibrium in the energy metabolism and has a modifiable nature, change body weight index, adjust feature of fat metabolism, reduce adipose factor maladjusted, have benefited greatly to performing cancer prevention and cure.

\section{Immunotherapy}

Obesity has become a risk factor for an attenuated anti-tumor immune landscape. Obesity may up-regulate the pro-inflammatory adipokines and down-regulate the anti-inflammatory adipokines expression levels, leading to an excessive adipokine secretion and a persistent immune imbalance accompanied by a chronic inflammatory. Importantly, the characteristics and functions of immune cells have undergone largely impaired biological changes with the obese state (142). The tumor-killing effector cells (CD8+ T) were suppressed and the immunosuppressor cells (MDSCs/M2) were over-activated to drive their recruitment and suppressive capacity, which could be mediated by obesity-related molecular markers, such as IL-6, CRP, leptin, IL-1 $\beta$. 
For instance, in elderly mice given systemic anti-tumor immunotherapy, obesity caused a fatal cytokine storm, which increased M1 macrophage polarization, and proinflammatory TNF- $\alpha$ and IL- 6 release, leading to a reduced anti-tumor effect and low survival rate (143). PD-L1 has been shown to be overexpressed $\mathrm{BC}$ than in normal breast tissue and is closely associated with tumor immune surveillance and prognosis. Wang et al. found that obesity or metabolic syndrome-related M1 macrophages up-regulated PD-L1 expression in TNBC by partially secreting IL-6 in a JAK/STAT-dependent pathway, which in turn affected immunotherapy targeting the PD-L1/ PD-1 axis in vitro (144). Gibson et al. firstly identified the effect of obesity on MDSC-mediated immunotherapy resistance in a BC mouse tumor model and found that obesity could lead to the accumulation of FasL+ granulocytic MDSCs, thus promoting apoptosis of tumor-Infiltrating CD8 T cells and immunotherapy (adenovirus encoding TRAIL $+\mathrm{CpG}$ ) resistance in BC (145). It posed a novel pathway of MDSC-related resistance and its disruption may improve immunotherapy outcomes in patients with $\mathrm{BC}$ and obesity.

Overweight and obese women with $\mathrm{BC}$ are prone to acquire worse clinical outcomes with antibody-based immunotherapy, which has been confirmed by some clinical studies. The inherent associations potentially operating to link obesity and prognosis in $\mathrm{BC}$ are complex. The adipocyte secretion-associated alteration in obesity, including the changes in the ratio of leptin to adiponectin, the expression levels of pro-inflammatory cytokines, IGFs, and estrogen, may be the mechanisms potentially leading to $\mathrm{BC}$ immunotherapy resistance. For example, Ado-trastuzumab emtansine (T-DM1) is a novel antibody-drug conjugate suitable for the treatment of HER2+ BC. In obese patients receiving T-DM1 might require more treatment modifications secondary to adverse events compared to non-obese patients (146). In a cohort of HER2metastatic BC patients treated with first-line paclitaxel and bevacizumab, Pizzuti et al. found that BMI did not affect overall response rate or disease control rate in the overall patient cohort, but higher disease control rate associated with $\mathrm{BMI} \geq 25 \mathrm{~kg} / \mathrm{m} 2$ in TNBC patients (147). Furthermore, in the NeoALTTO study treated with neoadjuvant lapatinib, trastuzumab, or their combination plus paclitaxel, obesity was associated with reduced access to pCR in HER2+ luminal BC patients, but not in HER2cases (118). In a multicentre observational cohort study, Eriseld et al. suggested that class I obesity was correlated with a worse OS in HER2+ metastatic BC patients treated with pertuzumab and/or trastuzumab emtansine (148).

On the other hand, immunotherapy side effects in these patients caused by obesity should be closely monitored and effectively managed. In addition, in a retrospective cohort study, obesity might be a risk factor of cardiotoxicity in HER2+ BC patients receiving trastuzumab, indicating the necessity to prevent cardiotoxicity when receiving this regimen for patients with obesity and other risk factors (149). Furthermore, Wang et al. also addressed the predictive value of obesity and affirmed that obesity was an independent risk factor of trastuzumab-related cardiac toxicity in elderly BC patients who received trastuzumab therapy (150).
Totally, obesity may exert different effects depending on the tumor type, immunotherapy method, and patient cohorts, which is attributed to a variety of lifestyle, clinical and pathological factors, emphasizing the significance of obesity as an important evaluation factor for BC immunotherapy efficacy and side effects. These findings pave the way to future research in taking into account patient BMI, in clinical modification of combined immunotherapy strategies aimed at obtaining an ideal clinical outcome.

\section{Weight Management}

Observational evidence has linked physical inactivity and obesity to an increased risk of $\mathrm{BC}$ and a poor outcome in BC. Recent studies have revealed that weight management or interventions via diet, physical activity, bariatric surgery could be important determinants of BC risk and outcomes (151-157). As Lee et al. reported that a 16-week of supervised aerobic and resistance exercise interventions could decrease the 10-year risk of cardiovascular disease in early BC women who were overweight or obese (158). In the study of Sweeney et al., a 16week exercise significantly promoted the shoulder function in overweight or obese women after BC treatment (159).

Physical activity can improve the health outcomes of $\mathrm{BC}$ survivors by affecting insulin, IGF, insulin resistance, glucose metabolism, sex hormones, adipokines, inflammatory factors, oxidative stress, and DNA damage repair ability (160). A randomized controlled trial displayed that a 16 -week aerobic and resistance exercise intervention could reduce M1 ATMs and adipose tissue secretion of the pro-inflammatory cytokines IL-6 and TNF- $\alpha$, and increase M2 ATMs and secretion of antiinflammatory cytokines such as adiponectin in obese postmenopausal BC survivors (161). The HFD-fed and ovariectomized mice showed a reduced anti-oxidative response and inflammation in TME, accompanied by the change of adiponectin and leptin in different tissues (162). It indicated that in the case of obesity, spontaneous physical activity could repress tumor progress by the interplay of adipose tissue, muscle and tumor tissue. Besides, diet and exercise interventions implemented in overweight/obese BC survivors may improve metabolic risk, insulin resistance and leptin biomarkers. Travier et al. designed a study that provided a 12-week diet and exercise program for overweight/obese BC survivors (154). the metabolic risk markers and insulin resistance indicators of $\mathrm{BC}$ survivors were significantly improved, while the reduction in leptin was not significant while adiponectin was significantly reduced. In another 18-month weight-loss trial of overweight/obese BC survivors women who lost $>10 \%$ exhibited a significantly increased expression in serum adiponectin, as well as the improved adiponectin at 6 to 18 months despite weight regain (163). Achieving this level of weight loss appeared to be related to the regulation of adiponectin and was of great significance to the overall adipokine environment including the adiponectin/leptin ratio, insulin and PAI-1. Interestingly, Adams et al. enrolled 2 trials about the novel miRNAs that involved in BMI and weight loss in BC development (164). The results showed that obesity could affect the expression of tumor-associated miRNAs, 
highlight the potential mechanisms of the positive relationship between BMI and BC risk. Therefore, moderate-to-vigorous intensity resistance and aerobic exercise play positive roles in attenuating adipose tissue inflammation in obese $\mathrm{BC}$ patients, which could be beneficial for controlling BC.

\section{CONCLUSION}

Collectively, a large increasing body of evidence strongly verifies obesity as a known risk factor for $\mathrm{BC}$ initiation and progression. The prevalence of obesity is posing challenges in $\mathrm{BC}$ incidence control and management considerations. Obesity is a very complex abnormal state, accompanied by various physiological and molecular alterations, which involves the complicated roles of adipokines (leptin, adiponectin, resistin, visfatin, and SFRP5), insulin, IGF, sex hormone, and chronic inflammation. These factors will synthetically affect cell proliferation, angiogenesis alteration, oncogene activation, oxidative stress, and immune cell dysfunction, which capable of regulating the behavior of BC cells and BC TME, ultimately. Targeting adipocyte-derived factors may be a feasible therapeutic approach to improving the prognosis of obese patients. On the other hand, obesity has recently been explored to present treatment resistance and potential drug side effects in various BC regimens, including surgery, RT, chemotherapy, ET, immunotherapy, and weight management, posing challenges for the maximum efficacy and minimum side effects of BC therapy (Figure 2).

Nevertheless, there are still some challenges to be addressed in terms of obesity and BC. First of all, although the interest in obesity and $\mathrm{BC}$ carcinogenesis gains momentum, the mechanism studies of obesity-triggered BC in favor of BC prevention and therapy are still investigational. Inflammation of adipose tissue may contribute to BC independently of obesity. More thorough and ongoing studies with large-scale in the future are warranted to decipher the interrelationships and roles that underlie the obesity-derived factors and BC conundrum. Secondly, in different BC subtypes, especially the high incidence TNBC and HER2+ BC, the relationship between obesity and prognosis is unclear and the conclusions are not quite consistent. This might attribute to the fact that obesity involves many confounding factors including age, the presence or absence of CLSs, population, menopausal status, and molecular type of the tumor. It means that the influence extent and difference of obesity on the treatment and prognosis of these $\mathrm{BC}$ subtypes remains to be clarified. Thirdly, obesity might counteract the

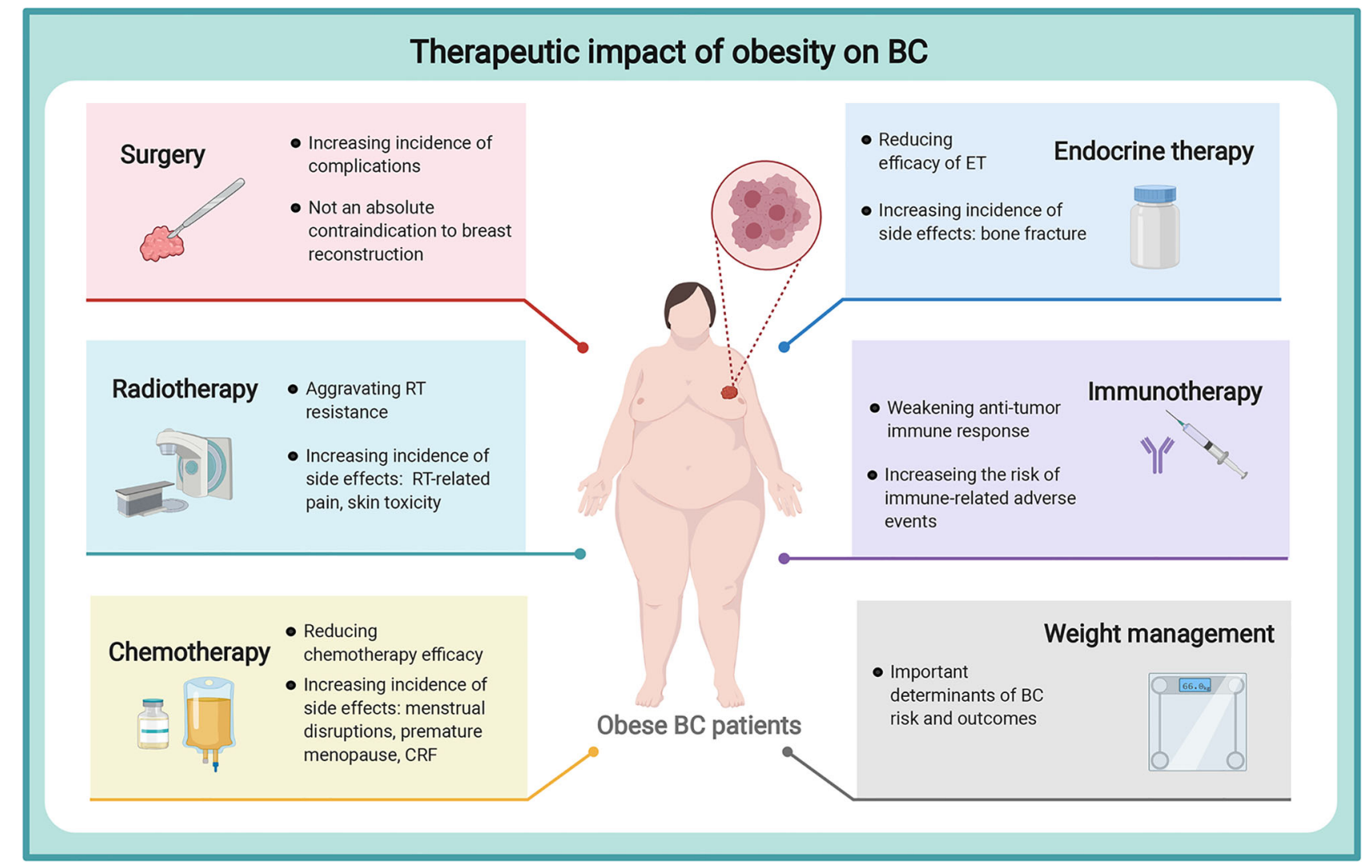

FIGURE 2 | Therapeutic impact of obesity on breast cancer. Obesity could aggravate treatment resistance and potential drug side effects in various BC treatments, including surgery, RT, chemotherapy, ET, immunotherapy, and weight management, posing challenges for the maximum efficacy and minimum side effects of BC therapy. breast cancer, BC, breast cancer; RT, radiotherapy; CRF, cancer-related fatigue; ET, endocrine therapy. The figure was created with BioRender.com. 
benefits of BC treatment and raise the possible side effects. Some of the associations with adverse outcomes may have to do with poor therapeutic doses in obese patients due to dose-limiting toxicity. Attention needs to be paid to individualized dosing and close monitoring of treatment for BC patients with obese states. Of cause, lifestyle interventions via weight control, such as exercise, weight loss, and alimentary control, are considered as emerging approaches for better prevention and survival of $\mathrm{BC}$ patients. Fourthly, BMI is an index for weight in large amounts of studies. But BMI is defined only in relation to weight and height, which actually lacks body composition measure. Sometimes BMI might be inaccurate in defining obesity or emaciation. Therefore, the definition of body composition patterns and biomarkers related to the true nature induced by obesity is necessary for more accurate verification. Besides, key biomarkers of risk are still lacking in obesity-related BC prevention, although ongoing studies have been devoted to this area. The identification of more specific biomarkers will provide mechanistic insight into predicting the response to effect, adverse reaction, and resistance of combined targeted therapies of BC patients with obesity. At last, a comprehensive understanding of the biological mechanisms of

\section{REFERENCES}

1. Sung H, Ferlay J, Siegel RL, Laversanne M, Soerjomataram I, Jemal A, et al. Global Cancer Statistics 2020: GLOBOCAN Estimates of Incidence and Mortality Worldwide for 36 Cancers in 185 Countries. CA Cancer J Clin (2021) 68(6):caac.21660. doi: 10.3322/caac.21660

2. Ponnusamy L, Natarajan SR, Thangaraj K, Manoharan R. Therapeutic Aspects of AMPK in Breast Cancer: Progress, Challenges, and Future Directions. Biochim Biophys Acta - Rev Cancer (2020) 1874(1):188379. doi: 10.1016/j.bbcan.2020.188379

3. Pi-Sunyer FX, Becker DM, Bouchard C, Carleton RA, Colditz GA, Dietz WH, et al. Clinical Guidelines on the Identification, Evaluation, and Treatment of Overweight and Obesity in Adults: Executive Summary. Expert Panel on the Identification, Evaluation, and Treatment of Overweight in Adults. Am J Clin Nutr (1998) 68(4):899-917. doi: 10.1093/ajcn/68.4.899

4. Heetun A, Cutress RI, Copson ER. Early Breast Cancer: Why Does Obesity Affect Prognosis? Proc Nutr Soc (2018) 77(4):369-81. doi: 10.1017/ S0029665118000447

5. Azrad M, Blair CK, Rock CL, Sedjo RL, Wolin KY, Demark-Wahnefried W. Adult Weight Gain Accelerates the Onset of Breast Cancer. Breast Cancer Res Treat (2019) 176(3):649-56. doi: 10.1007/s10549-019-05268-y

6. Gribsholt SB, Cronin-Fenton D, Veres K, Thomsen RW, Ording AG, Richelsen B, et al. Hospital-Diagnosed Overweight and Obesity Related to Cancer Risk: A 40-Year Danish Cohort Study. J Intern Med (2020) 287 (4):435-47. doi: 10.1111/joim.13013

7. Park JW, Han K, Shin DW, Yeo Y, Chang JW, Yoo JE, et al. Obesity and Breast Cancer Risk for Pre- and Postmenopausal Women Among Over 6 Million Korean Women. Breast Cancer Res Treat (2021) 185(2):495-506. doi: 10.1007/s10549-020-05952-4

8. Rose DP, Vona-davis L. Maturitas Interaction Between Menopausal Status and Obesity in Affecting Breast Cancer Risk. Maturitas (2010) 66(1):33-8. doi: 10.1016/j.maturitas.2010.01.019

9. Amadou A, Ferrari P, Muwonge R, Moskal A, Biessy C, Romieu I, et al. Overweight, Obesity and Risk of Premenopausal Breast Cancer According to Ethnicity: A Systematic Review and Dose-Response Meta-Analysis. Obes Rev (2013) 14(8):665-78. doi: 10.1111/obr.12028

10. Cao S, Zhou J, Zhu Z, Wei F, Li W, Lu S, et al. Adult Weight Change and the Risk of Pre- and Postmenopausal Breast Cancer in the Chinese Wuxi Exposure and Breast Cancer Study. Breast Cancer Res Treat (2019) 173 (3):647-55. doi: 10.1007/s10549-018-5016-3 obesity on treatment effectiveness and tolerance is necessary for maximizing the efficacy of $\mathrm{BC}$ therapy. Addressing the obesity state will allow the improvement of more personalized and effective prevention and treatment strategies for BC.

\section{AUTHOR CONTRIBUTIONS}

$\mathrm{CZ}, \mathrm{WH}$, and $\mathrm{YX}$ performed the literature search and wrote the manuscript. HW, QZ, and YPW conceived the project and revised the manuscript. DW, YCW, WL, MX, and YY edited the manuscript. All authors contributed to the article and approved the submitted version.

\section{FUNDING}

This section acknowledges contributions from the China GuangHua Science and Technology Foundation (No. 2019JZXM001) and Wuhan Science and Technology Bureau (No. 2020020601012241).

11. Parr CL, Batty GD, Lam TH, Barzi F, Fang X, Ho SC, et al. Body-Mass Index and Cancer Mortality in the Asia-Pacific Cohort Studies Collaboration: Pooled Analyses of 424519 Participants. Lancet Oncol (2010) 11:741-52. doi: 10.1016/S1470-2045(10)70141-8

12. Jeong SH, An Y, Ahn C, Park B, Lee MH, Noh D-Y, et al. Body Mass Index and Risk of Breast Cancer Molecular Subtypes in Korean Women: A CaseControl Study. Breast Cancer Res Treat (2020) 179(2):459-70. doi: 10.1007/ s10549-019-05451-1

13. Nindrea R, Aryandono T, Lazuardi L, Dwiprahasto I. Association of Overweight and Obesity With Breast Cancer During Premenopausal Period in Asia: A Meta-Analysis. Int J Prev Med (2019) 10(1):192. doi: 10.4103/ijpvm.IJPVM_372_18

14. Rush EC, Freitas I, Plank LD. Body Size, Body Composition and Fat Distribution: Comparative Analysis of European, Maori, Pacific Island and Asian Indian Adults. Br J Nutr (2009) 102:632-41. doi: 10.1017/ S0007114508207221

15. Uomori T, Horimoto Y, Arakawa A, Iijima K, Saito M, et al. Breast Cancer in Lean Postmenopausal Women Might Have Specific Pathological Features. (2019) 33(2):483-7. doi: 10.21873/invivo.11499

16. Nattenmüller CJ, Kriegsmann M, Sookthai D, Fortner RT, Steffen A, Walter B, et al. Obesity as Risk Factor for Subtypes of Breast Cancer: Results From a Prospective Cohort Study. BMC Cancer (2018) 18(1):616. doi: 10.1186/s12885-018-4548-6

17. Shu X, Wu L, Khankari NK, Shu X-O, Wang TJ, Michailidou K, et al. Associations of Obesity and Circulating Insulin and Glucose With Breast Cancer Risk: A Mendelian Randomization Analysis. Int J Epidemiol (2019) 48(3):795-806. doi: 10.1093/ije/dyz013

18. Liu C-R, Li Q, Hou C, Li H, Shuai P, Zhao M, et al. Changes in Body Mass Index, Leptin, and Leptin Receptor Polymorphisms and Breast Cancer Risk. DNA Cell Biol (2018) 37(3):182-8. doi: 10.1089/dna.2017.4047

19. Zhang K, Luo Y, Dai H, Deng Z. Effects of Bariatric Surgery on Cancer Risk: Evidence From Meta-Analysis. Obes Surg (2020) 30(4):1265-72. doi: 10.1007/s11695-019-04368-4

20. Vernaci G, Dieci MV, Manfrin S, Mantiero M, Falci C, Faggioni G, et al. BMI Is an Independent Prognostic Factor for Late Outcome in Patients Diagnosed With Early Breast Cancer: A Landmark Survival Analysis. Breast (2019) 47:77-84. doi: 10.1016/j.breast.2019.07.003

21. Kim JY, Lee D-W, Lee K-H, Min A, Ryu HS, Lee H-B, et al. Prognostic Role of Body Mass Index Is Different According to Menopausal Status and Tumor Subtype in Breast Cancer Patients. Breast Cancer Res Treat (2019) 176 (2):453-60. doi: 10.1007/s10549-019-05249-1 
22. Alarcón Rojas CA, Alvarez-Bañuelos MT, Morales-Romero J, Suárez-Díaz H, Hernández-Fonseca JC, Contreras-Alarcón G, et al. Breast Cancer: Metastasis, Molecular Subtypes, and Overweight and Obesity in Veracruz, Mexico. Clin Breast Cancer (2019) 19(1):e166-71. doi: 10.1016/ j.clbc.2018.08.003

23. Wang X, Hui T-L, Wang M-Q, Liu H, Li RY, Song ZC, et al. Body Mass Index at Diagnosis as a Prognostic Factor for Early-Stage Invasive Breast Cancer After Surgical Resection. Oncol Res Treat (2019) 42(4):195-201. doi: $10.1159 / 000496548$

24. Cacho-Díaz B, Spínola-Maroño H, Reynoso N, González-Aguilar A, MoharBetancourt A, et al. Role of Overweight, Obesity, and Comorbidities in the Prognosis of Patients With Breast Cancer With Brain Metastases. Clin Breast Cancer (2019) 19(2):e394-8. doi: 10.1016/j.clbc.2018.12.018

25. Patel V, James M, Frampton C, Robinson B, Davey V, Timmings L, et al. Body Mass Index and Outcomes in Breast Cancer Treated With Breast Conservation. Int J Radiat Oncol (2020) 106(2):369-76. doi: 10.1016/ j.ijrobp.2019.09.049

26. Tenvooren I, Jenks MZ, Rashid H, Cook KL, Muhlemann JK, Sistrunk C, et al. Elevated Leptin Disrupts Epithelial Polarity and Promotes Premalignant Alterations in the Mammary Gland. Oncogene (2019) 38 (20):3855-70. doi: 10.1038/s41388-019-0687-8

27. Mahbouli S, Talvas J, der Vartanian A, Ortega S, Rougé S, Vasson M-P, et al. Activation of Antioxidant Defences of Human Mammary Epithelial Cells Under Leptin Depend on Neoplastic State. BMC Cancer (2018) 18(1):1264. doi: 10.1186/s12885-018-5141-8

28. Juárez-Cruz JC, Zuñiga-Eulogio MD, Olea-Flores M, Castañeda-Saucedo E, Mendoza-Catalán M, Ortuño-Pineda C, et al. Leptin Induces Cell Migration and Invasion in a FAK-Src-Dependent Manner in Breast Cancer Cells. Endocr Connect (2019) 8(11):1539-52. doi: 10.1101/631143

29. Haque I, Ghosh A, Acup S, Banerjee S, Dhar K, Ray A, et al. Leptin-Induced ER- $\alpha$-Positive Breast Cancer Cell Viability and Migration Is Mediated by Suppressing CCN5-Signaling via Activating JAK/AKT/STAT-Pathway. BMC Cancer (2018) 18(1):99. doi: 10.1186/s12885-018-3993-6

30. Sabol RA, Bowles AC, Côté A, Wise R, O'Donnell B, Matossian MD, et al. Leptin Produced by Obesity-Altered Adipose Stem Cells Promotes Metastasis But Not Tumorigenesis of Triple-Negative Breast Cancer in Orthotopic Xenograft and Patient-Derived Xenograft Models. Breast Cancer Res (2019) 21(1):67. doi: 10.1186/s13058-019-1153-9

31. Ramos-Andrade I, Moraes J, Brandão-Costa RM, Vargas da Silva S, de Souza A, da Silva C, et al. Obese Adipose Tissue Extracellular Vesicles Raise Breast Cancer Cell Malignancy. Endocr Relat Cancer (2020) 27(10):571-82. doi: 10.1530/ERC-19-0507

32. Bowers LW, Rossi EL, McDonell SB, Doerstling SS, Khatib SA, Lineberger CG, et al. Leptin Signaling Mediates Obesity-Associated CSC Enrichment and EMT in Preclinical TNBC Models. Mol Cancer Res (2018) 16(5):869-79. doi: 10.1158/1541-7786.MCR-17-0508

33. Yadav NVS, Barcikowski A, Uehana Y, Jacobs AT, Connelly L, et al. Breast Adipocyte Co-Culture Increases the Expression of Pro-Angiogenic Factors in Macrophages. Front Oncol (2020) 10(April):1-12. doi: 10.3389/ fonc.2020.00454

34. Evangelista GCM, Salvador PA, Soares SMA, Barros LRC, Xavier FH, Abdo LM, et al. 4t1 Mammary Carcinoma Colonization of Metastatic Niches Is Accelerated by Obesity. Front Oncol (2019) 9(September):1-12. doi: 10.3389/fonc. 2019.00685

35. Zhang C, Yue C, Herrmann A, Song J, Egelston C, Wang T, et al. STAT3 Activation-Induced Fatty Acid Oxidation in CD8+ T Effector Cells Is Critical for Obesity-Promoted Breast Tumor Growth. Cell Metab (2020) 31(1):148-61.e5. doi: 10.1016/j.cmet.2019.10.013

36. Clements VK, Long T, Long R, Figley C, Smith DMC, Ostrand-Rosenberg S, et al. Frontline Science: High Fat Diet and Leptin Promote Tumor Progression by Inducing Myeloid-Derived Suppressor Cells. J Leukoc Biol (2018) 103(3):395-407. doi: 10.1002/JLB.4HI0517-210R

37. Bouguerra H, Amal G, Clavel S, Boussen H, Louet J-F, Gati A, et al. Leptin Decreases Susceptibility BC Cells to NK-Lysis via PGC-1 $\alpha$ Pathway. Endocr Connect (2020) 9(6):578-86. doi: 10.1530/EC-20-0109

38. Duan L, Lu Y, Xie W, Nong L, Jia Y, Tan A, et al. Leptin Promotes Bone Metastasis of Breast Cancer by Activating the SDF-1/CXCR4 Axis. Aging (Albany NY) (2020) 12(16):16172-82. doi: 10.18632/aging.103599
39. Gelsomino L, Naimo GD, Malivindi R, Augimeri G, Panza S, Giordano C, et al. Knockdown of Leptin Receptor Affects Macrophage Phenotype in the Tumor Microenvironment Inhibiting Breast Cancer Growth and Progression. Cancers (Basel) (2020) 12(8):2078. doi: 10.3390/ cancers 12082078

40. Ecker BL, Lee JY, Sterner CJ, Solomon AC, Pant DK, Shen F, et al. Impact of Obesity on Breast Cancer Recurrence and Minimal Residual Disease. Breast Cancer Res (2019) 21(1):41. doi: 10.1186/s13058-018-1087-7

41. Mauro L, Naimo GD, Gelsomino L, Malivindi R, Bruno L, Pellegrino M, et al. Uncoupling Effects of Estrogen Receptor $\alpha$ on LKB1/AMPK Interaction Upon Adiponectin Exposure in Breast Cancer. FASEB J (2018) 32(8):4343-55. doi: 10.1096/fj.201701315R

42. Mahmoud EH, Fawzy A, El-Din WM, Shafik NF. Diagnostic Value of Adiponectin Gene Polymorphism and Serum Level in Postmenopausal Obese Patients With Breast Cancer. J Cancer Res Ther (2020) 16(6):1269-73.

43. Pasha HF, Mohamed RH, Toam MM, Yehia AM. Genetic and Epigenetic Modifications of Adiponectin Gene: Potential Association With Breast Cancer Risk. J Gene Med (2019). doi: 10.1002/jgm.3120

44. Wang C-Q, Tang C-H, Tzeng H-E, Jin L, Zhao J, Kang L, et al. Impacts of RETN Genetic Polymorphism on Breast Cancer Development. J Cancer (2020) 11(10):2769-77. doi: 10.7150/jca.38088

45. Rosendahl AH, Bergqvist $\mathrm{M}$, Lettiero B, Kimbung S, Borgquist $\mathrm{S}$, et al. Adipocytes and Obesity-Related Conditions Jointly Promote Breast Cancer Cell Growth and Motility: Associations With CAP1 for Prognosis. Front Endocrinol (Lausanne) (2018). doi: 10.3389/fendo.2018.00689

46. Avtanski D, Garcia A, Caraballo B, Thangeswaran P, Marin S, Bianco J, et al. Resistin Induces Breast Cancer Cells Epithelial to Mesenchymal Transition (EMT) and Stemness Through Both Adenylyl Cyclase-Associated Protein 1 (CAP1)-Dependent and CAP1-Independent Mechanisms. Cytokine (2019) 120(January):155-64. doi: 10.1016/j.cyto.2019.04.016

47. Wang C-H, Wang P-J, Hsieh Y-C, Lo S, Lee Y-C, Chen Y-C, et al. Resistin Facilitates Breast Cancer Progression via TLR4-Mediated Induction of Mesenchymal Phenotypes and Stemness Properties. Oncogene (2018) 37 (5):589-600. doi: 10.1038/onc.2017.357

48. Gholinejad Z, Kheiripour N, Nourbakhsh M, Ilbeigi D, Behroozfar K, Hesari Z, et al. Extracellular NAMPT/Visfatin Induces Proliferation Through ERK1/2 and AKT and Inhibits Apoptosis in Breast Cancer Cells. Peptides (2017) 92:9-15. doi: 10.1016/j.peptides.2017.04.007

49. Zhou W, Ye C, Li L, Wang F, Yu L, Zhou F, et al. Adipocyte-Derived SFRP5 Inhibits Breast Cancer Cells Migration and Invasion Through Wnt and Epithelial-Mesenchymal Transition Signaling Pathways. Chin J Cancer Res (2020) 32(3):347-60. doi: 10.21147/j.issn.1000-9604.2020.03.06

50. Pan H, Deng L-L, Cui J-Q, Shi L, Yang Y-C, Luo J-H, et al. Association Between Serum Leptin Levels and Breast Cancer Risk. Med (Baltimore) (2018) 97(27):e11345. doi: 10.1097/MD.0000000000011345

51. Spielmann J, Mattheis L, Jung JS, Rauße H, Glaß M, Bähr I, et al. Effects of Obesity on NK Cells in a Mouse Model of Postmenopausal Breast Cancer. Sci Rep (2020) 10(1):1-14. doi: 10.1038/s41598-020-76906-5

52. Gelsomino L, Naimo GD, Catalano S, Mauro L, Andò S, et al. The Emerging Role of Adiponectin in Female Malignancies. Int J Mol Sci (2019) 20(9):2127. doi: 10.3390/ijms20092127

53. Patrício M, Pereira J, Crisóstomo J, Matafome P, Gomes M, Seiça R, et al. Using Resistin, Glucose, Age and BMI to Predict the Presence of Breast Cancer. BMC Cancer (2018) 18(1):29. doi: 10.1186/s12885-017-3877-1

54. Gao Y, Chen X, He Q, Gimple RC, Liao Y, Wang L, et al. Adipocytes Promote Breast Tumorigenesis Through TAZ-Dependent Secretion of Resistin. Proc Natl Acad Sci (2020) 117(52):33295-304. doi: 10.1073/ pnas. 2005950117

55. Kabat GC, Kim MY, Lane DS, Zaslavsky O, Ho GYF, Luo J, et al. Serum Glucose and Insulin and Risk of Cancers of the Breast, Endometrium, and Ovary in Postmenopausal Women. Eur J Cancer Prev (2018) 27(3):261-8. doi: 10.1097/CEJ.0000000000000435

56. Park J, Morley TS, Kim M, Clegg DJ, Scherer PE, et al. Obesity and CancerMechanisms Underlying Tumour Progression and Recurrence. Nat Rev Endocrinol (2014) 10(8):455-65. doi: 10.1038/nrendo.2014.94

57. Björner S, Rosendahl AH, Simonsson M, Markkula A, Jirström K, Borgquist $S$, et al. Body Mass Index Influences the Prognostic Impact of Combined Nuclear Insulin Receptor and Estrogen Receptor Expression in Primary 
Breast Cancer. Front Endocrinol (Lausanne) (2017) 8(NOV):1-13. doi: 10.3389/fendo.2017.00332

58. Valentino E, Bellazzo A, Di Minin G, Sicari D, Apollonio M, Scognamiglio G, et al. Mutant P53 Potentiates the Oncogenic Effects of Insulin by Inhibiting the Tumor Suppressor DAB2IP. Proc Natl Acad Sci (2017) 114 (29):7623-8. doi: 10.1073/pnas.1700996114

59. Rabin-Court A, Rodrigues MR, Zhang X-M, Perry RJ. Obesity-Associated, But Not Obesity-Independent, Tumors Respond to Insulin by Increasing Mitochondrial Glucose Oxidation. PloS One (2019) 14(6):e0218126. doi: 10.1371/journal.pone. 0218126

60. Rodriguez-Monterrosas C, Diaz-Aragon R, Cortes-Reynosa P, Salazar EP. Linoleic Acid Induces an Increased Response to Insulin in MDA-MB-231 Breast Cancer Cells. J Cell Biochem (2018) 119(7):5413-25. doi: 10.1002/ jcb. 26694

61. Luque RM, López-Sánchez LM, Villa-Osaba A, Luque IM, Santos-Romero $\mathrm{AL}$, Yubero-Serrano EM, et al. Breast Cancer Is Associated to Impaired Glucose/Insulin Homeostasis in Premenopausal Obese/Overweight Patients. Oncotarget (2017) 8(46):81462-74. doi: 10.18632/oncotarget.20399

62. Tong $\mathrm{Y}, \mathrm{Wu}$ J, Huang $\mathrm{O}, \mathrm{He} J$, Zhu L, Chen W, et al. IGF-1 Interacted With Obesity in Prognosis Prediction in HER2-Positive Breast Cancer Patients. Front Oncol (2020) 10(April):1-10. doi: 10.3389/fonc.2020.00550

63. Hillers LE, D'Amato JV, Chamberlin T, Paderta G, Arendt LM, et al. Obesity-Activated Adipose-Derived Stromal Cells Promote Breast Cancer Growth and Invasion. Neoplasia (2018) 20(11):1161-74. doi: 10.1016/ j.neo.2018.09.004

64. Kakugawa Y, Tada H, Kawai M, Suzuki T, Nishino Y, Kanemura S, et al. Associations of Obesity and Physical Activity With Serum and Intratumoral Sex Steroid Hormone Levels Among Postmenopausal Women With Breast Cancer: Analysis of Paired Serum and Tumor Tissue Samples. Breast Cancer Res Treat (2017) 162(1):115-25. doi: 10.1007/s10549-016-4094-3

65. Stone SA, Han CJ, Senn T, Korde LA, Allott K, Reding S, et al. Sex Hormones in Women With Elevated Breast Cancer Risk Undergoing Weight Loss. West J Nurs Res (2019) 41(11):1602-22. doi: 10.1177/0193945918820672

66. Gucalp A, Zhou XK, Cook ED, Garber JE, Crew KD, Nangia JR, et al. A Randomized Multicenter Phase II Study of Docosahexaenoic Acid in Patients With a History of Breast Cancer, Premalignant Lesions, or Benign Breast Disease. Cancer Prev Res (2018) 11(4):203-14. doi: 10.1158/ 1940-6207.CAPR-17-0354

67. Subbaramaiah K, Iyengar NM, Morrow M, Elemento O, Zhou XK, Dannenberg AJ, et al. Prostaglandin E2 Down-Regulates Sirtuin 1 (SIRT1), Leading to Elevated Levels of Aromatase, Providing Insights Into the Obesity-Breast Cancer Connection. J Biol Chem (2019) 294(1):361-71. doi: $10.1074 /$ jbc.RA118.005866

68. Sabol RA, Beighley A, Giacomelli P, Wise RM, Harrison MAA, O'Donnnell BA, et al. Obesity-Altered Adipose Stem Cells Promote ER+ Breast Cancer Metastasis Through Estrogen Independent Pathways. Int J Mol Sci (2019) 20 (6):1419. doi: 10.3390/ijms20061419

69. Zhao H, Wang J, Fang D, Lee O, Chatterton RT, Stearns V, et al. Adiposity Results in Metabolic and Inflammation Differences in Premenopausal and Postmenopausal Women Consistent With the Difference in Breast Cancer Risk. Horm Cancer (2018) 9(4):229-39. doi: 10.1007/s12672-018-0329-6

70. Qureshi R, Picon-Ruiz M, Aurrekoetxea-Rodriguez I, Nunes de Paiva V, D'Amico M, Yoon H, et al. The Major Pre- and Postmenopausal Estrogens Play Opposing Roles in Obesity-Driven Mammary Inflammation and Breast Cancer Development. Cell Metab (2020) 31(6):1154-72.e9. doi: 10.1016/ j.cmet.2020.05.008

71. Wang X, Simpson ER, Brown KA. Aromatase Overexpression in Dysfunctional Adipose Tissue Links Obesity to Postmenopausal Breast Cancer. J Steroid Biochem Mol Biol (2015) 153:35-44. doi: 10.1016/j.jsbmb.2015.07.008

72. Iyengar NM, Brown KA, Zhou XK, Gucalp A, Subbaramaiah K, Giri DD, et al. Metabolic Obesity, Adipose Inflammation and Elevated Breast Aromatase in Women With Normal Body Mass Index. Cancer Prev Res (2017) 10(4):235-43. doi: 10.1158/1940-6207.CAPR-16-0314

73. Martínez-Chacón G, Yatkin E, Polari L, Deniz Dinç D, Peuhu E, Hartiala P, et al. CC Chemokine Ligand 2 (CCL2) Stimulates Aromatase Gene Expression in Mammary Adipose Tissue. FASEB J (2021) 35(5):1-12. doi: 10.1096/fj.201902485RRR
74. Samarajeewa NU, Yang F, Docanto MM, Sakurai M, McNamara KM, Sasano H, et al. HIF- $1 \alpha$ Stimulates Aromatase Expression Driven by Prostaglandin E2in Breast Adipose Stroma. Breast Cancer Res (2013) 15(2):1-12. doi: $10.1186 / \mathrm{bcr} 3410$

75. Zahid H, Subbaramaiah K, Iyengar NM, Zhou XK, Chen IC, Bhardwaj P, et al. Leptin Regulation of the P53-HIF1 $\alpha /$ PKM2-Aromatase Axis in Breast Adipose Stromal Cells: A Novel Mechanism for the Obesity-Breast Cancer Link. Int J Obes (2018) 42(4):711-20. doi: 10.1038/ijo.2017.273

76. Martínez-Chacón G, Brown KA, Docanto MM, Kumar H, Salminen S, Saarinen N, et al. IL-10 Suppresses TNF- $\alpha$-Induced Expression of Human Aromatase Gene in Mammary Adipose Tissue. FASEB J (2018) 32(6):336170. doi: 10.1096/fj.201700938RRR

77. Subbaramaiah K, Howe LR, Bhardwaj P, Du B, Gravaghi C, Yantiss RK, et al. Obesity Is Associated With Inflammation and Elevated Aromatase Expression in the Mouse Mammary Gland. Cancer Prev Res (2011) 4 (3):329-46. doi: 10.1158/1940-6207.CAPR-10-0381

78. Gonçalves RM, Delgobo M, Agnes JP, das Neves RN, Falchetti M, Casagrande T, et al. COX-2 Promotes Mammary Adipose Tissue Inflammation, Local Estrogen Biosynthesis, and Carcinogenesis in HighSugar/Fat Diet Treated Mice. Cancer Lett (2021) 502(September 2020):4457. doi: 10.1016/j.canlet.2021.01.003

79. Bowers LW, Brenner AJ, Hursting SD, Tekmal RR, DeGraffenried LA, et al. Obesity-Associated Systemic Interleukin-6 Promotes Pre-Adipocyte Aromatase Expression via Increased Breast Cancer Cell Prostaglandin E2 Production. Breast Cancer Res Treat (2015) 149(1):49-57. doi: 10.1007/ s10549-014-3223-0

80. Nagahashi M, Yamada A, Katsuta E, Aoyagi T, Huang W-C, Terracina KP, et al. Targeting the SphK1/S1P/S1PR1 Axis That Links Obesity, Chronic Inflammation, and Breast Cancer Metastasis. Cancer Res (2018) 78(7):171325. doi: 10.1158/0008-5472.CAN-17-1423

81. Zhao Y-X, Sun Y-L, Ye J-H, Zhang Y, Shi X-B, Wang J-M, et al. The Relationship Between White Adipose Tissue Inflammation and Overweight/ Obesity in Chinese Female Breast Cancer: A Retrospective Study. Adv Ther (2020) 37(6):2734-47. doi: 10.1007/s12325-020-01368-0

82. Sheean P, Gomez-Perez S, Joyce C, Vasilopoulos V, Bartolotta MB, Robinson P, et al. Body Composition, Serum Biomarkers of Inflammation and Quality of Life in Clinically Stable Women With Estrogen Receptor Positive Metastatic Breast Cancer. Nutr Cancer (2019) 71(6):981-91. doi: 10.1080/01635581.2019.1595053

83. Christodoulatos GS, Spyrou N, Kadillari J, Psallida S, Dalamaga M, et al. The Role of Adipokines in Breast Cancer: Current Evidence and Perspectives. Curr Obes Rep (2019) 8(4):413-33. doi: 10.1007/s13679-019-00364-y

84. AL-Jawadi A, Moussa H, Ramalingam L, Dharmawardhane S, Gollahon L, Gunaratne P, et al. Protective Properties of N-3 Fatty Acids and Implications in Obesity-Associated Breast Cancer. J Nutr Biochem (2018) 53:1-8. doi: 10.1016/j.jnutbio.2017.09.018

85. Hillers-Ziemer LE, McMahon RQ, Hietpas M, Paderta G, LeBeau J, McCready J, et al. Obesity Promotes Cooperation of Cancer Stem-Like Cells and Macrophages to Enhance Mammary Tumor Angiogenesis. Cancers (Basel) (2020) 12(2):502. doi: 10.3390/cancers12020502

86. Faria SS, Corrêa LH, Heyn GS, de Sant'Ana LP, Almeida RDN, Magalhães KG, et al. Obesity and Breast Cancer: The Role of Crown-Like Structures in Breast Adipose Tissue in Tumor Progression, Prognosis, and Therapy. $J$ Breast Cancer (2020) 23(3):233-45. doi: 10.4048/jbc.2020.23.e35

87. Maliniak ML, Cheriyan AM, Sherman ME, Liu Y, Gogineni K, Liu J, et al. Detection of Crown-Like Structures in Breast Adipose Tissue and Clinical Outcomes Among African-American and White Women With Breast Cancer. Breast Cancer Res (2020) 22:65. doi: 10.1186/s13058-020-01308-4

88. Kolb R, Zhang W. Obesity and Breast Cancer: A Case of Inflamed Adipose Tissue. Cancers (Basel) (2020) 12(6):1686. doi: 10.3390/cancers12061686

89. Wilcz-Villega E, Carter E, Ironside A, Xu R, Mataloni I, Holdsworth J, et al. Macrophages Induce Malignant Traits in Mammary Epithelium via Ikke/ TBK1 Kinases and the Serine Biosynthesis Pathway. EMBO Mol Med (2020) 12(2):1-20. doi: 10.15252/emmm.201910491

90. Tiwari P, Blank A, Cui C, Schoenfelt KQ, Zhou G, Xu Y, et al. Metabolically Activated Adipose Tissue Macrophages Link Obesity to Triple-Negative Breast Cancer. J Exp Med (2019) 216(6):1345-58. doi: 10.1084/jem.20181616 
91. Kolb R, Kluz P, Tan ZW, Borcherding N, Bormann N, Vishwakarma A, et al. Obesity-Associated Inflammation Promotes Angiogenesis and Breast Cancer via Angiopoietin-Like 4. Oncogene (2019) 38(13):2351-63. doi: 10.1038/s41388-018-0592-6

92. Cranford TL, Velázquez KT, Enos RT, Sougiannis AT, Bader JE, Carson MS, et al. Effects of High Fat Diet-Induced Obesity on Mammary Tumorigenesis in the PyMT/MMTV Murine Model. Cancer Biol Ther (2019) 20(4):487-96. doi: 10.1080/15384047.2018.1537574

93. Belaiba F, Medimegh I, Ammar M, Jemni F, Mezlini A, Romdhane K, et al. Expression and Polymorphism of Micro-RNA According to Body Mass Index and Breast Cancer Presentation in Tunisian Patients. J Leukoc Biol (2019) 105(2):317-27. doi: 10.1002/JLB.3VMA0618-218R

94. Collier W, Scheefer Van Boerum M, Kim J, Kwok AC. Are 30-Day Outcomes Enough? Late Infectious Readmissions Following ProstheticBased Breast Reconstruction. Plast. Reconstr. Surg (2019) 144(3):360e-8e. doi: $10.1097 /$ PRS. 0000000000005903

95. Sinha I, Pusic AL, Wilkins EG, Hamill JB, Chen X, Kim HM, et al. Late Surgical-Site Infection in Immediate Implant-Based Breast Reconstruction. Plast Reconstr Surg (2017) 139(1):20-8. doi: 10.1097/PRS.0000000000002839

96. Michalik T, Matkowski R, Biecek P, Szynglarewicz B. The Use of Ultrasonic Scalpel Lowers the Risk of Post-Mastectomy Seroma Formation in Obese Women. J Cancer (2019) 10(15):3481-5. doi: 10.7150/jca.29774

97. Oliveira MMF de, Gurgel MSC, Amorim BJ, Ramos CD, Derchain S, FurlanSantos N, et al. Long Term Effects of Manual Lymphatic Drainage and Active Exercises on Physical Morbidities, Lymphoscintigraphy Parameters and Lymphedema Formation in Patients Operated Due to Breast Cancer: A Clinical Trial. PloS One (2018) 13(1):e0189176. doi: 10.1371/ journal.pone.0189176

98. Wang M, Huang J, Chagpar AB. Do Obese Breast Cancer Patients Have More Complications and a Longer Length of Stay After Mastectomy Than Nonobese Patients? Am Surg (2020) 000313482097335. doi: 10.1177/ 0003134820973352

99. Exarchos G, Metaxa L, Constantinidou A, Kontos M. Delayed Breast Cellulitis Following Surgery for Breast Cancer: A Literature Review. Breast Care (2019) 14(1):48-52. doi: 10.1159/000494691

100. Panayi A, Agha R, Sieber B, Orgill D. Impact of Obesity on Outcomes in Breast Reconstruction: A Systematic Review and Meta-Analysis. J Reconstr Microsurg (2018) 34(05):363-75. doi: 10.1055/s-0038-1627449

101. Garland M, Hsu F-C, Clark C, Chiba A, Howard-McNatt M, et al. The Impact of Obesity on Outcomes for Patients Undergoing Mastectomy Using the ACS-NSQIP Data Set. Breast Cancer Res Treat (2018) 168(3):723-6. doi: 10.1007/s10549-017-4651-4

102. Ding Y-Y, Yao P, Wu L, Han Z-K, Hong T, Zhu Y-Q, et al. Body Mass Index and Persistent Pain After Breast Cancer Surgery: Findings From the Women's Healthy Eating and Living Study and a Meta-Analysis. Oncotarget (2017) 8(26):43332-43. doi: 10.18632/oncotarget.17948

103. Klement KA, Hijjawi JB, LoGiudice JA, Alghoul M, Omesiete-Adejare P, et al. Microsurgical Breast Reconstruction in the Obese: A Better Option Than Tissue Expander/Implant Reconstruction? Plast Reconstr Surg (2019) 144(3):539-46. doi: 10.1097/PRS.0000000000005897

104. Chang EI, Liu J. Prospective Evaluation of Obese Patients Undergoing Autologous Abdominal Free Flap Breast Reconstruction. Plast Reconstr Surg (2018) 142(2):120e-5e. doi: 10.1097/PRS.0000000000004550

105. Rudolph M, Moore C, Pestana IA. Operative Risk Stratification in the Obese Female Undergoing Implant-Based Breast Reconstruction. Breast J (2019) 25 (6):1182-6. doi: 10.1111/tbj.13434

106. Lee E, Nelson OL, Puyana C, Takita C, Wright JL, Zhao W, et al. Association Between C-Reactive Protein and Radiotherapy-Related Pain in a Tri-Racial/ Ethnic Population of Breast Cancer Patients: A Prospective Cohort Study. Breast Cancer Res (2019) 21(1):70. doi: 10.1186/s13058-019-1151-y

107. Hu JJ, Urbanic JJ, Case LD, Takita C, Wright JL, Brown DR, et al. Association Between Inflammatory Biomarker C-Reactive Protein and RadiotherapyInduced Early Adverse Skin Reactions in a Multiracial/Ethnic Breast Cancer Population. J Clin Oncol (2018) 36(24):2473-82. doi: 10.1200/JCO.2017.77.1790

108. McCall NS, Simone BA, Mehta M, Zhan T, Ko K, Nowak-Choi K, et al. Onco-Metabolism: Defining the Prognostic Significance of Obesity and Diabetes in Women With Brain Metastases From Breast Cancer. Breast Cancer Res Treat (2018) 172(1):221-30. doi: 10.1007/s10549-018-4880-1
109. Sabol RA, Villela VA, Denys A, Freeman BT, Hartono AB, Wise RM, et al. Obesity-Altered Adipose Stem Cells Promote Radiation Resistance of Estrogen Receptor Positive Breast Cancer Through Paracrine Signaling. Int J Mol Sci (2020) 21(8):2722. doi: 10.3390/ijms 21082722

110. Mentoor I, Engelbrecht A-M, Nell T. Fatty Acids: Adiposity and Breast Cancer Chemotherapy, a Bad Synergy? Prostaglandins, Leukot. Essent Fat Acids (2019) 140(January 2018):18-33. doi: 10.1016/j.plefa.2018.11.009

111. Lehuédé C, Li X, Dauvillier S, Vaysse C, Franchet C, Clement E, et al. Adipocytes Promote Breast Cancer Resistance to Chemotherapy, a Process Amplified by Obesity: Role of the Major Vault Protein (MVP). Breast Cancer Res (2019) 21(1):7. doi: 10.1186/s13058-018-1088-6

112. Liu Z, Shi A, Song D, Han B, Zhang Z, Ma L, et al. Resistin Confers Resistance to Doxorubicin-Induced Apoptosis in Human Breast Cancer Cells Through Autophagy Induction. Am J Cancer Res (2017) 7(3):574-83.

113. Mentoor I, Nell T, Emjedi Z, van Jaarsveld PJ, de Jager L, Engelbrecht A-M, et al. Decreased Efficacy of Doxorubicin Corresponds With Modifications in Lipid Metabolism Markers and Fatty Acid Profiles in Breast Tumors From Obese vs. Lean Mice. Front Oncol (2020) 10(March):1-21. doi: 10.3389/ fonc. 2020.00306

114. Yeo W, Pang E, Liem GS, Suen JJS, Ng RYW, Yip CCH, et al. Menopausal Symptoms in Relationship to Breast Cancer-Specific Quality of Life After Adjuvant Cytotoxic Treatment in Young Breast Cancer Survivors. Health Qual Life Outcomes (2020) 18(1):24. doi: 10.1186/s12955-020-1283-x

115. Collins JM, Fleming GF, Christ TN. Comparison of the Incidence of Febrile Neutropenia in Obese and Normal Weight Breast Cancer Patients Receiving Myelosuppressive Chemotherapy and Prophylactic Pegfilgrastim. J Oncol Pharm Pract (2019) 25(5):1112-8. doi: 10.1177/1078155218776471

116. Inglis JE, Janelsins MC, Culakova E, Mustian KM, Lin P-J, Kleckner IR, et al. Longitudinal Assessment of the Impact of Higher Body Mass Index on Cancer-Related Fatigue in Patients With Breast Cancer Receiving Chemotherapy. Support Care Cancer (2020) 28(3):1411-8. doi: 10.1007/ s00520-019-04953-4

117. Karatas F, Erdem GU, Sahin S, Aytekin A, Yuce D, Sever AR, et al. Obesity Is an Independent Prognostic Factor of Decreased Pathological Complete Response to Neoadjuvant Chemotherapy in Breast Cancer Patients. Breast (2017) 32:237-44. doi: 10.1016/j.breast.2016.05.013

118. Di Cosimo S, Porcu L, Agbor-tarh D, Cinieri S, Franzoi MA, De Santis MC, et al. Effect of Body Mass Index on Response to Neo-Adjuvant Therapy in HER2-Positive Breast Cancer: An Exploratory Analysis of the NeoALTTO Trial. Breast Cancer Res (2020) 22(1):115. doi: 10.1186/s13058-020-01356-w

119. Farr A, Stolz M, Baumann L, Bago-Horvath Z, Oppolzer E, Pfeiler G, et al. The Effect of Obesity on Pathological Complete Response and Survival in Breast Cancer Patients Receiving Uncapped Doses of Neoadjuvant Anthracycline-Taxane-Based Chemotherapy. Breast (2017) 33:153-8. doi: 10.1016/j.breast.2017.04.001

120. Méndez-Hernández A, Gallegos-Arreola MP, Moreno-Macías H, Espinosa Fematt J, Pérez-Morales R, et al. LEP Rs7799039, LEPR Rs1137101, and ADIPOQ Rs2241766 and 1501299 Polymorphisms Are Associated With Obesity and Chemotherapy Response in Mexican Women With Breast Cancer. Clin Breast Cancer (2017) 17(6):453-62. doi: 10.1016/j.clbc.2017.03.010

121. Griggs JJ, Mangu PB, Anderson H, Balaban EP, Dignam JJ, Hryniuk WM, et al. Appropriate Chemotherapy Dosing for Obese Adult Patients With Cancer: American Society of Clinical Oncology Clinical Practice Guideline. J Clin Oncol (2012) 30(13):1553-61. doi: 10.1200/JCO.2011.39.9436

122. Morrison VA, McCall L, Muss HB, Jatoi A, Cohen HJ, Cirrincione CT, et al. The Impact of Actual Body Weight-Based Chemotherapy Dosing and Body Size on Adverse Events and Outcome in Older Patients With Breast Cancer: Results From Cancer and Leukemia Group B (CALGB) Trial 49907 (Alliance A151436). J Geriatr Oncol (2018) 9(3):228-34. doi: 10.1016/j.jgo.2017.11.007

123. Matikas A, Foukakis T, Moebus V, Greil R, Bengtsson NO, Steger GG, et al. Dose Tailoring of Adjuvant Chemotherapy for Breast Cancer Based on Hematologic Toxicities: Further Results From the Prospective PANTHER Study With Focus on Obese Patients. Ann Oncol (2019) 30(1):109-14. doi: 10.1093/annonc/mdy475

124. Dalasanur Nagaprashantha L, Adhikari R, Singhal J, Chikara S, Awasthi S, Horne D, et al. Translational Opportunities for Broad-Spectrum Natural Phytochemicals and Targeted Agent Combinations in Breast Cancer. Int $J$ Cancer (2018) 142(4):658-70. doi: 10.1002/ijc.31085 
125. Hagen KB, Aas T, Kvaløy JT, Søiland H, Lind R, et al. Adherence to Adjuvant Endocrine Therapy in Postmenopausal Breast Cancer Patients: A 5-Year Prospective Study. Breast (2019) 44:52-8. doi: 10.1016/j.breast.2019.01.003

126. Lee K, Kruper L, Dieli-Conwright CM, Mortimer JE. The Impact of Obesity on Breast Cancer Diagnosis and Treatment. Curr Oncol Rep (2019) 21(5):41. doi: 10.1007/s11912-019-0787-1

127. Liu YL, Saraf A, Catanese B, Lee SM, Z-ng Y, Connolly EP, et al. Obesity and Survival in the Neoadjuvant Breast Cancer Setting: Role of Tumor Subtype in an Ethnically Diverse Population. Breast Cancer Res Treat (2018) 167 (1):277-88. doi: 10.1007/s10549-017-4507-y

128. Zewenghiel L, Lindman H, Valachis A. Impact of Body Mass Index on the Efficacy of Endocrine Therapy in Patients With Metastatic Breast Cancer - A Retrospective Two-Center Cohort Study. Breast (2018) 40:136-40. doi: 10.1016/j.breast.2018.05.005

129. Pedersini R, Amoroso V, Maffezzoni F, et al. Association of Fat Body Mass With Vertebral Fractures in Postmenopausal Women With Early Breast Cancer Undergoing Adjuvant Aromatase Inhibitor Therapy. JAMA Netw Open (2019) 2(9):e1911080. doi: 10.1001/jamanetworkopen.2019.11080

130. Schech A, Yu S, Goloubeva O, et al. A Nude Mouse Model of Obesity to Study the Mechanisms of Resistance to Aromatase Inhibitors. Endocr Relat Cancer (2015) 22(4):645-56. doi: 10.1530/ERC-15-0168

131. Delort L, Bougaret L, Cholet J, Vermerie M, Billard H, Decombat C, et al. Hormonal Therapy Resistance and Breast Cancer: Involvement of Adipocytes and Leptin. Nutrients (2019) 11(12):2839. doi: 10.3390/nu11122839

132. Wellberg EA, Kabos P, Gillen AE, Jacobsen BM, Brechbuhl HM, Johnson SJ, et al. FGFR1 Underlies Obesity-Associated Progression of Estrogen Receptor-Positive Breast Cancer After Estrogen Deprivation. JCI Insight (2018) 3:1-17. doi: 10.1172/jci.insight.120594

133. Ambrosio MR, D'Esposito V, Costa V, Liguoro D, Collina F, Cantile M, et al. Glucose Impairs Tamoxifen Responsiveness Modulating Connective Tissue Growth Factor in Breast Cancer Cells. Oncotarget (2017) 8(65):109000-17. doi: 10.18632/oncotarget.22552

134. Morgan MM, Arendt LM, Alarid ET, Beebe DJ, Johnson BP, et al. Mammary Adipose Stromal Cells Derived From Obese Women Reduce Sensitivity to the Aromatase Inhibitor Anastrazole in an Organotypic Breast Model. FASEB J (2019) 33(7):8623-33. doi: 10.1096/fj.201802347RRR

135. Strong AL, Ohlstein JF, Biagas BA, Rhodes LV, Pei DT, Tucker HA, et al. Leptin Produced by Obese Adipose Stromal/Stem Cells Enhances Proliferation and Metastasis of Estrogen Receptor Positive Breast Cancers. Breast Cancer Res (2015) 17:1-16. doi: 10.1186/s13058-015-0622-Z

136. Bougaret L, Delort L, Billard H, Le Huede C, Boby C, De la Foye A, et al. Adipocyte/breast Cancer Cell Crosstalk in Obesity Interferes With the AntiProliferative Efficacy of Tamoxifen. PloS One (2018) 13(2):e0191571. doi: 10.1371/journal.pone.0191571

137. Linares RL, Benítez JGS, Reynoso MO, Romero CG, Sandoval-Cabrera A, et al. Modulation of the Leptin Receptors Expression in Breast Cancer Cell Lines Exposed to Leptin and Tamoxifen. Sci Rep (2019) 9(1):19189. doi: 10.1038/s41598-019-55674-x

138. Papanikolaou V, Stefanou N, Dubos S, Papathanasiou I, Palianopoulou M, Valiakou V. Synergy of Leptin/STAT3 With HER2 Receptor Induces Tamoxifen Resistance in Breast Cancer Cells Through Regulation of ApoptosisRelated Genes. Cell Oncol (2015) 38:155-64. doi: 10.1007/s13402-014-0213-5

139. Qian Y, Shi D, Qiu J, Zhu F, Qian J, He S, et al. ObRb Downregulation Increases Breast Cancer Cell Sensitivity to Tamoxifen. Tumor Biol (2015) 36 (9):6813-21. doi: 10.1007/s13277-015-3375-5

140. Gelsomino L, Giordano C, La Camera G, Sisci D, Marsico S, Campana A, et al. Leptin Signaling Contributes to Aromatase Inhibitor Resistant Breast Cancer Cell Growth and Activation of Macrophages. Biomolecules (2020) 10 (4):543. doi: 10.3390/biom 10040543

141. Barone I, Giordano C, Bonofiglio D, Andò S, Catalano S, et al. Leptin, Obesity and Breast Cancer: Progress to Understanding the Molecular Connections. Curr Opin Pharmacol (2016) 31:83-9. doi: 10.1016/j.coph.2016.10.003

142. Naik A, Monjazeb AM, Decock J. The Obesity Paradox in Cancer, Tumor Immunology, and Immunotherapy: Potential Therapeutic Implications in Triple Negative Breast Cancer. Front Immunol (2019). doi: 10.3389/ fimmu.2019.01940

143. Mirsoian A, Bouchlaka MN, Sckisel GD, Chen M, Pai CS, Maverakis E, et al. Adiposity Induces Lethal Cytokine Storm After Systemic Administration of
Stimulatory Immunotherapy Regimens in Aged Mice. J Exp Med (2014) 211: (12):2373-83. doi: 10.1084/jem.20140116

144. Wang Y, Zhang X, Xie X, Chen W, Li M, Diao D, et al. Obesity and Metabolic Syndrome Related Macrophage Promotes PD-L1 Expression in TNBC Through IL6/JAK/STAT Pathway and can be Reversed by Telmisartan. Cancer Biol Ther (2020) 21(12):1179-90. doi: 10.1080/15384047.2020.1838032

145. Gibson JT, Orlandella RM, Turbitt WJ, Behring M, Manne U, Sorge RE, et al. Obesity-Associated Myeloid-Derived Suppressor Cells Promote Apoptosis of Tumor-In Fi Ltrating CD8 T Cells and Immunotherapy Resistance in Breast Cancer. Front Immunol (2020) 11:1-13. doi: 10.3389/fimmu.2020.590794

146. Lee A, Larck C, Moore DC. Impact of Obesity on Safety Outcomes and Treatment Modifications With Ado-Trastuzumab Emtansine in Breast Cancer Patients. J Oncol Pharm Pract (2020) 107815522098264. doi: $10.1177 / 1078155220982648$

147. Pizzuti L, Sergi D, Sperduti I, Lauro L, Mazzotta M, Botti C, et al. Body Mass Index in HER2-Negative Metastatic Breast Cancer Treated With Fi Rst-Line Paclitaxel and Bevacizumab. Cancer Biol Ther (2018) 19:328-34. doi: 10.1080/15384047.2017.1416938

148. Krasniqi E, Pizzuti L, Barchiesi G, Sergi D, Carpano S, Botti C, et al. Impact of BMI on HER2+ Metastatic Breast Cancer Patients Treated With Pertuzumab and/or Trastuzumab Emtansine. Real-World Evidence. J Cell Physiol (2020) 235(11):7900-10. doi: 10.1002/jcp.29445

149. Kosalka P, Johnson C, Turek M, Sulpher J, Law A, Botros J, et al. Effect of Obesity, Dyslipidemia, and Diabetes on Trastuzumab-Related Cardiotoxicity in Breast Cancer. Curr Oncol (2019) 26(3):314-21. doi: 10.3747/co.26.4823

150. Wang H-Y, Yin B-B, Jia D-Y, Hou Y-L. Association Between Obesity and Trastuzumab-Related Cardiac Toxicity in Elderly Patients With Breast Cancer. Oncotarget (2017) 8(45):79289-97. doi: 10.18632/oncotarget.17808

151. Chlebowski RT, Luo J, Anderson GL, Barrington W, Reding K, Simon MS, et al. Weight Loss and Breast Cancer Incidence in Postmenopausal Women. Cancer (2019) 125(2):205-12. doi: 10.1002/cncr.31687

152. Winder AA, Kularatna M, MacCormick AD. Does Bariatric Surgery Affect the Incidence of Breast Cancer Development? A Systematic Review Obes Surg (2017) 27(11):3014-20. doi: 10.1007/s11695-017-2901-5

153. Hassinger TE, Mehaffey JH, Hawkins RB, Schirmer BD, Hallowell PT, Schroen AT, et al. Overall and Estrogen Receptor-Positive Breast Cancer Incidences Are Decreased Following Bariatric Surgery. Obes Surg (2019) 29 (3):776-81. doi: 10.1007/s11695-018-3598-9

154. Travier N, Buckland G, Vendrell JJ, Fernandez-Veledo S, Peiró I, del Barco S, et al. Changes in Metabolic Risk, Insulin Resistance, Leptin and Adiponectin Following a Lifestyle Intervention in Overweight and Obese Breast Cancer Survivors. Eur J Cancer Care (Engl) (2018) 27(4):e12861. doi: 10.1111/ ecc. 12861

155. Han CJ, Korde LA, Reding S, Allott K, Van Doren M, Schwarz Y, et al. Investigation of a Lifestyle Intervention in Women at High Risk of Breast Cancer. West J Nurs Res (2018) 40(7):976-96. doi: 10.1177/0193945917697227

156. Feigelson HS, Caan B, Weinmann S, Leonard AC, Powers JD, Yenumula PR, et al. Bariatric Surgery Is Associated With Reduced Risk of Breast Cancer in Both Premenopausal and Postmenopausal Women. Ann Surg (2020) 272 (6):1053-9. doi: 10.1097/SLA.0000000000003331

157. Cortesi L, Sebastiani F, Iannone A, Marcheselli L, Venturelli M, Piombino C, et al. Lifestyle Intervention on Body Weight and Physical Activity in Patients With Breast Cancer Can Reduce the Risk of Death in Obese Women: The EMILI Study. Cancers (Basel) (2020) 12(7):1709. doi: 10.3390/cancers12071709

158. Lee K, Tripathy D, Demark-Wahnefried W, Courneya KS, Sami N, Bernstein L, et al. Effect of Aerobic and Resistance Exercise Intervention on Cardiovascular Disease Risk in Women With Early-Stage Breast Cancer. JAMA Oncol (2019) 5(5):710. doi: 10.1001/jamaoncol.2019.0038

159. Sweeney FC, Demark-Wahnefried W, Courneya KS, Sami N, Lee K, Tripathy $\mathrm{D}$, et al. Aerobic and Resistance Exercise Improves Shoulder Function in Women Who Are Overweight or Obese and Have Breast Cancer: A Randomized Controlled Trial. Phys Ther (2019) 99(10):1334-45. doi: 10.1093/ptj/pzz096

160. Activity P, Control W. Physical Activity, Weight Control, and Biomarkers of Prognosis and Survival Among Breast Cancer Survivors. Arch Epidemiol (2018) 2(4):1-10. doi: 10.29011/2577-2252.000027

161. Dieli-Conwright CM, Parmentier JH, Sami N, Lee K, Spicer D, Mack WJ, et al. Adipose Tissue Inflammation in Breast Cancer Survivors: Effects of a 
16-Week Combined Aerobic and Resistance Exercise Training Intervention. Breast Cancer Res Treat (2018) 168(1):147-57. doi: 10.1007/s10549-0174576-y

162. Le Guennec D, Hatte V, Farges M-C, Rougé S, Goepp M, Caldefie-Chezet F, et al. Modulation of Inter-Organ Signalling in Obese Mice by Spontaneous Physical Activity During Mammary Cancer Development. Sci Rep (2020) 10 (1):8794. doi: 10.1038/s41598-020-65131-9

163. Befort CA, Kimler BF, Bantis LE, Phillips TA, Fabian CJ, et al. Effects of Weight Loss and Weight Regain on Circulating Biomarkers in Overweight/ Obese Breast Cancer Survivors Enrolled in a Weight Loss Trial in the Rural Midwest. Cancer Epidemiol Biomarkers Prev (2020) 29(7):1321-8. doi: 10.1158/1055-9965.EPI-19-1572

164. Adams BD, Arem H, Hubal MJ, Cartmel B, Li F, Harrigan M, et al. Exercise and Weight Loss Interventions and miRNA Expression in Women With
Breast Cancer. Breast Cancer Res Treat (2018) 170(1):55-67. doi: 10.1007/ s10549-018-4738-6

Conflict of Interest: The authors declare that the research was conducted in the absence of any commercial or financial relationships that could be construed as a potential conflict of interest.

Copyright (C) 2021 Zhao, Hu, Xu, Wang, Wang, Lv, Xiong, Yi, Wang, Zhang and Wu. This is an open-access article distributed under the terms of the Creative Commons Attribution License (CC BY). The use, distribution or reproduction in other forums is permitted, provided the original author(s) and the copyright owner(s) are credited and that the original publication in this journal is cited, in accordance with accepted academic practice. No use, distribution or reproduction is permitted which does not comply with these terms. 